\title{
POPULATION GROWTH AND ITS IMPACT ON ENVIRONMENTAL POTENTIALS \\ CASE STUDY: RIYADH CITY - KINGDOM OF SAUDI ARABIA
}

\author{
Dr. Abdel Aziz Naser El-dawsary \\ Associated Professor of Town Planning, Faculty of Architectural and Planning, \\ King Saoud University, Riyadh, Kingdom of Saudi Arabia
}

(Received June 24, 2006 Accepted July 6, 2006)

\begin{abstract}
This study aims at reviewing the rates of population growth for the kingdom of Saudi Arabia in general and for the city of Riyadh in particular. This case study is intended to evaluate the changes in growth over the last thirty years, and the extent of its environmental potentials and features such as valleys, mountains, hills, desert areas, and agricultural zones around the city. All that leads to a future vision of a balanced population map which avoids any negative impact. In addition to population growth and congestion, other impacts such as air pollution and noise which results from the heavy traffic generation and the sprawl of the city as the Riyadh's population increased to exceed four millions, and expected to reach 10.5 millions by $1442 \mathrm{H}$.
\end{abstract}

It is evident that there is a great need to examine the city's population growth within a comprehensive study of the Kingdom's regions which produces migration to the capital. This migration is primarily for job opportunities or for education pursuance or for medical treatment. The main input for this study is the five year plans, and the national urban strategies as well as the regional structural plans to ensure a balanced growth and to limit migrations to large cities, especially Riyadh which reached $8 \%$ population growth.

Dealing with population growth in Riyadh shall be viewed comprehensively at all levels; national, regional and local. This will be the way to avoid further deterioration of the problem and to ensure a better future environment.
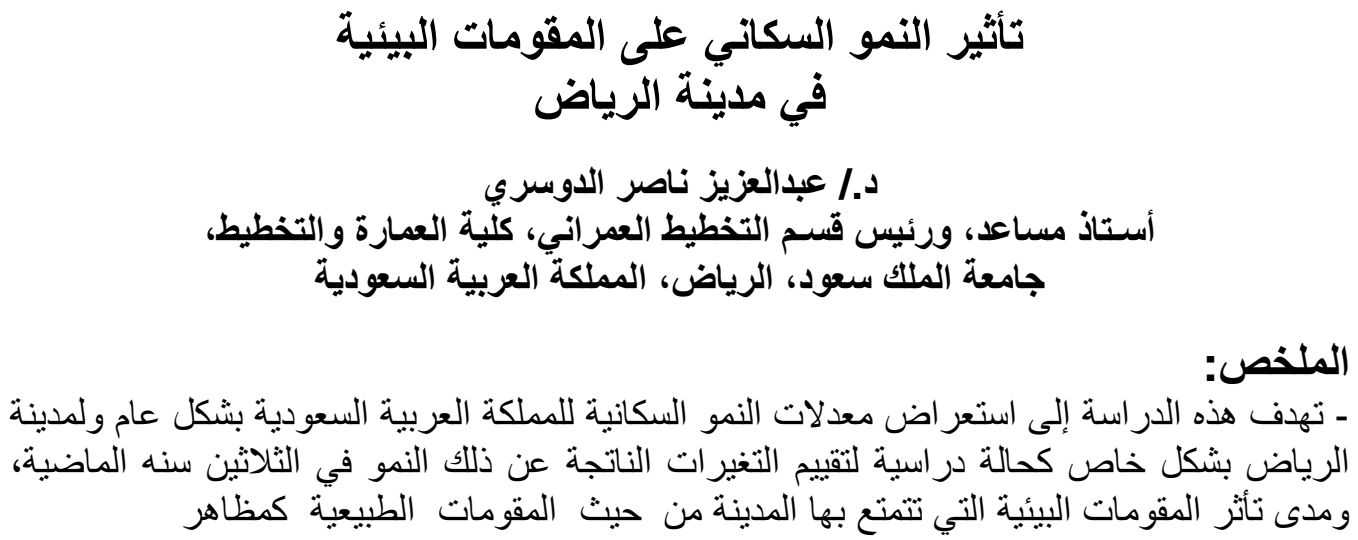
السطح مثل الأودية والجبال والتلال والمناطق الصحر اوية و الزر اعية المحيطة بالمدينة ووضع رؤية

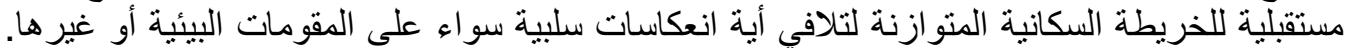

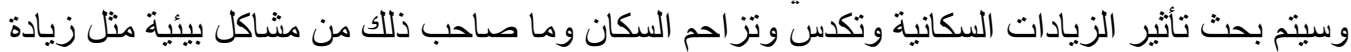

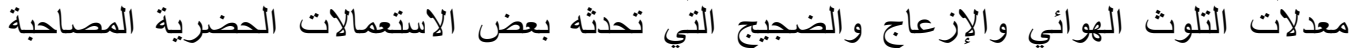

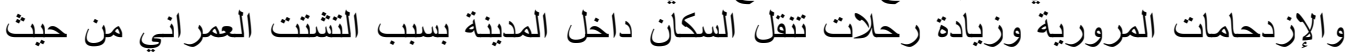

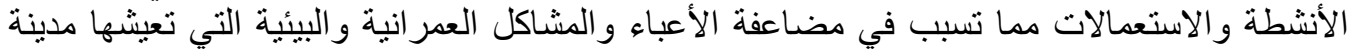

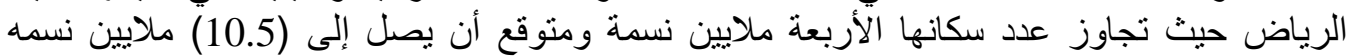
بحلول عام (1442هـ.)

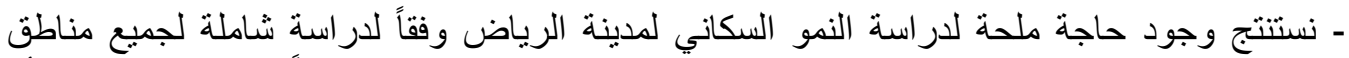

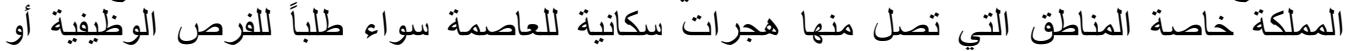

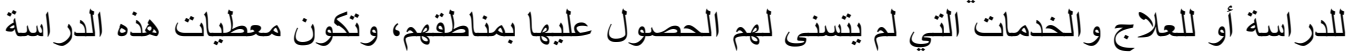

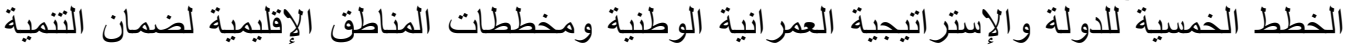

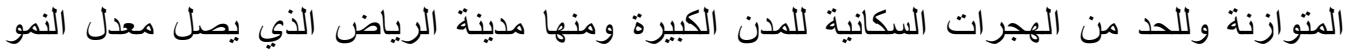

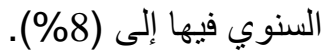

ـ لـذا يستوجب الأمر التعامل مع النمو السكاني في مدينة الرياض بنظرة شمولية وعلى جميع

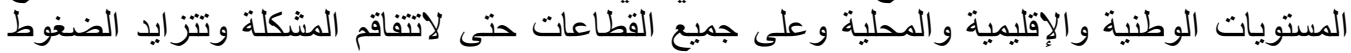

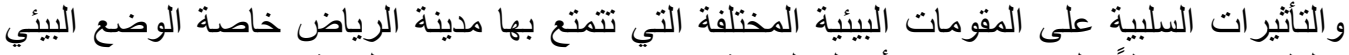
و الطبيعي وحفاظاً على مكتسبات الأجيال القادمة و عدم" استنز اف مواردهم الفي البيئية.

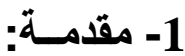

ـ تعتبر منطقة الرياض ثاني أكبر منطقة من حيث المساحة من المناطق الثلاثة عثر الإدارية بالمملكة

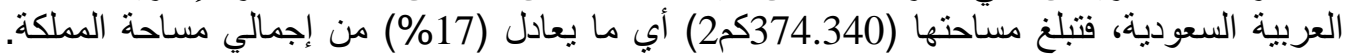

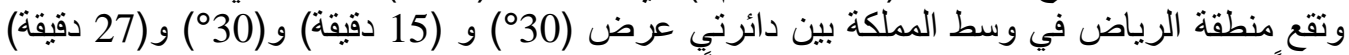

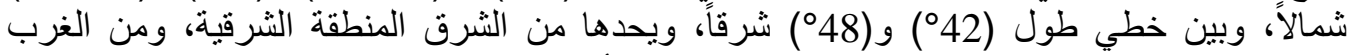

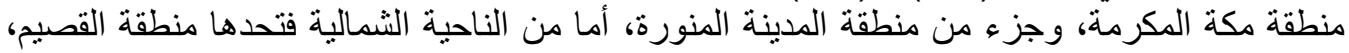

وجزء من منطقة حائل[1]].

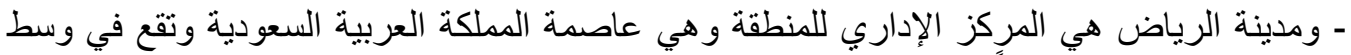

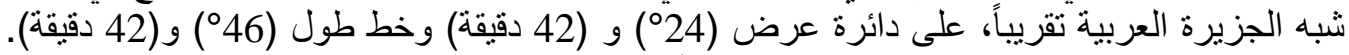

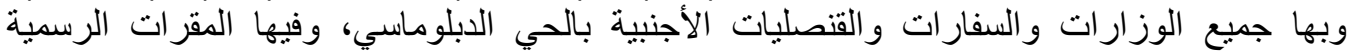

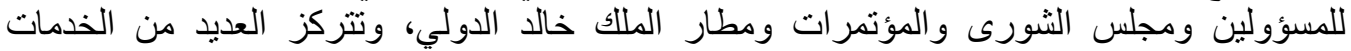

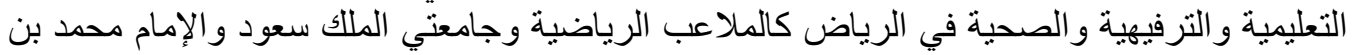

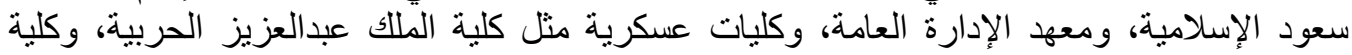

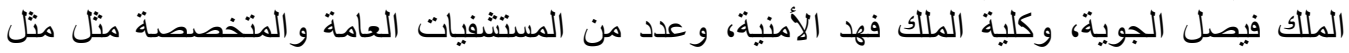
مستشفي الملك فيصل التخصصي، و الملك خالد الجامعي، ومستشفي الملك عبدالعزيز، و والملك خالد

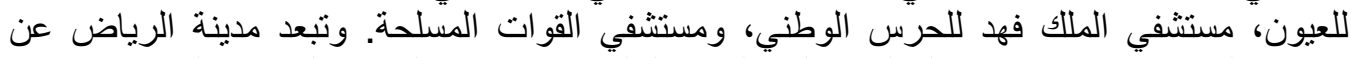

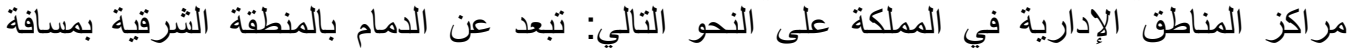

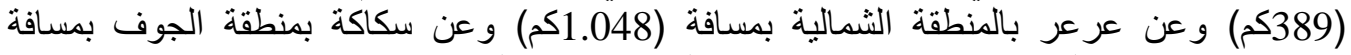

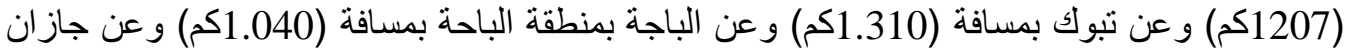

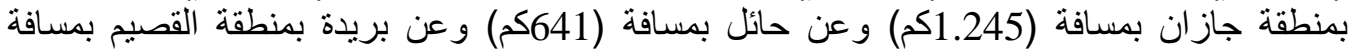

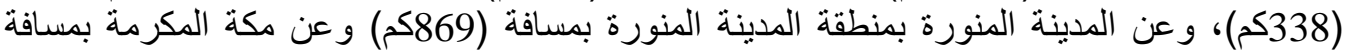

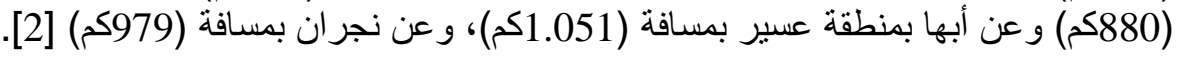


- وتعتبر مدينة الرياض و احدة من أسرع مدن العالم نمو آَّ حيث بيلغ عدد سكانها حو الي أربعة ملايين

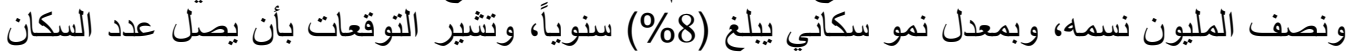

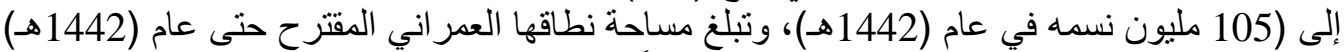

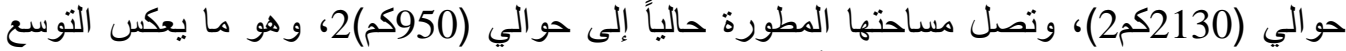
الكبير الذي نشهده المدينة لتصبح ضمن وأكبر ثناث مناطق حضرية في المملكة.

- إن هذا النمو المتسارع جعل الهيئة العليا لتطوير مدينة الرياض تقوم بعمل در اسات تخطيطية للمدينة،

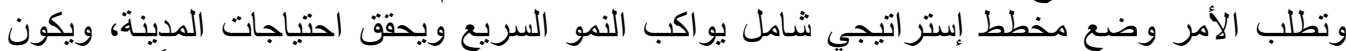
مظلة رئيسية للار اسات و الخطط و التصور ات المتعلقة بتطو ير وتتمية مدينة الرياض مستقبلاً، [3].

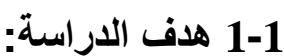
تهدف هذه الدراسة إلى استعر اض وتقيبيم معدلات النمو السكانية للمملكة العربية السعودية بشكل عام

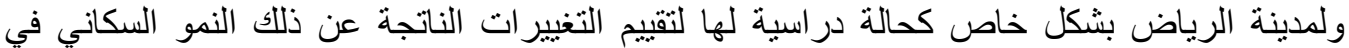

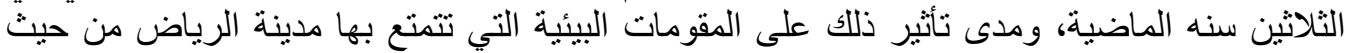

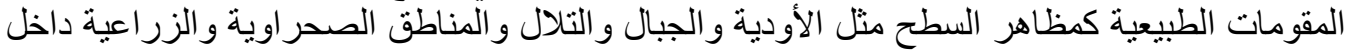

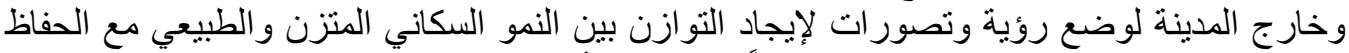

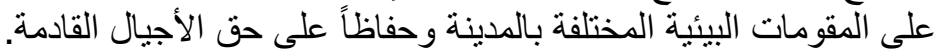

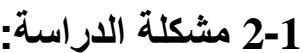

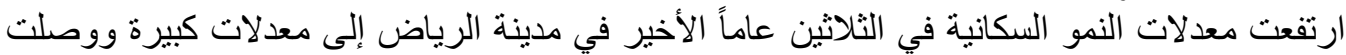
إلى أكثر من (8\%) كزيادة طبيعية وهجرات داخلية من مناطق المملكة المختلفة بالإضافة للألأعداد

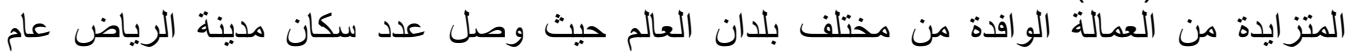

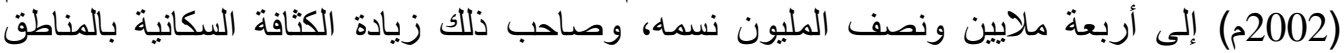

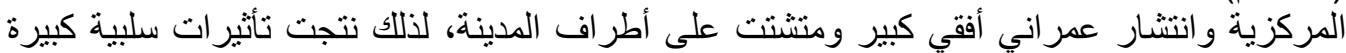

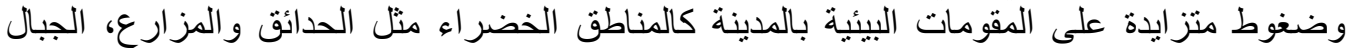

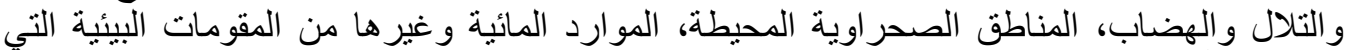
تأثرت سلباً بسبب هذه المعدلات العالية من النمو السكاني والتنمية العمر انية المصناحبة لهنة لها.

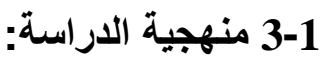

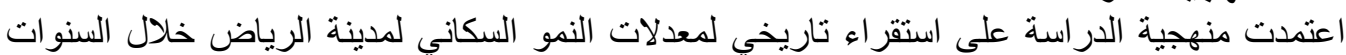

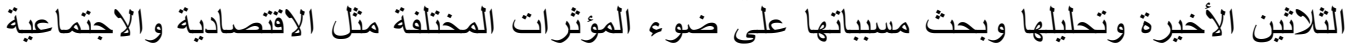

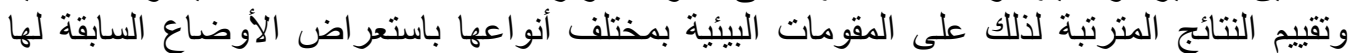
والتأثير ات التي حصلت عليها بسبب النمو السكاني المنز ايد في مدينة الرياض.

\section{4-1 منطقة الرياض بالنسبة للمناطق الإدارية في المملكة:}

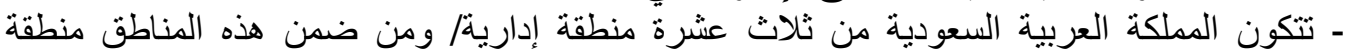

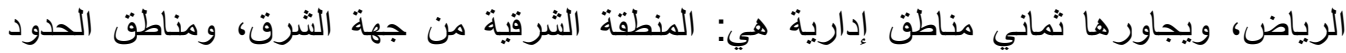

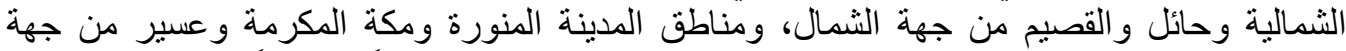

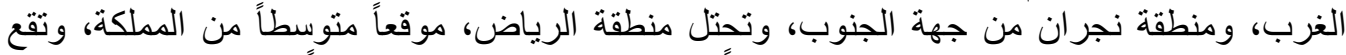

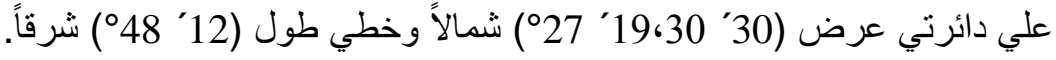

- منطقة الرياض الإدارية تتكون من مدينة الرياض وتسع عشرة محافظة تبلغ مساحتها الإجمالية (374.340كم2) ونتكل هذه المساحة حوالي (17\%) من المساحة الإجمالية للمملكة العربية السعودية، 
وتتفاوت محافظات منطقة الرياض من حيث المساحة ويمكن تصنيفها في ثلاث فئات: محافظات

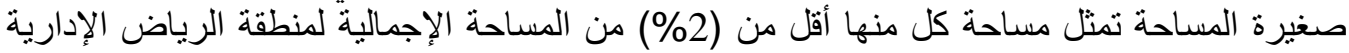

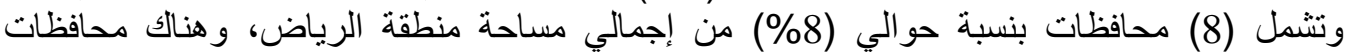

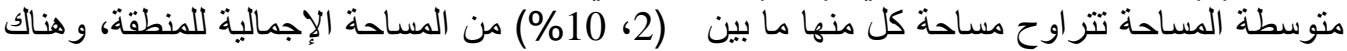

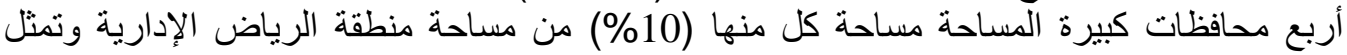
(52\%) من إجمالي مساحة المنطقة.

\section{التوزيع السكاني لمحافظات منطقة الرياض:}

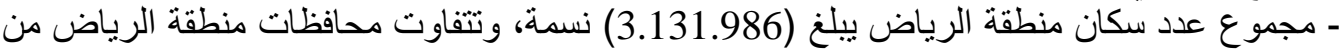

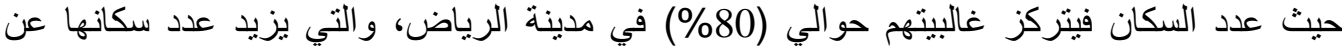

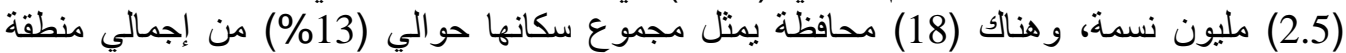

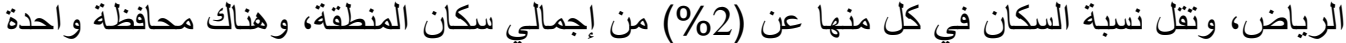

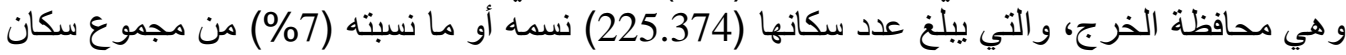

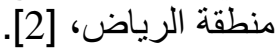

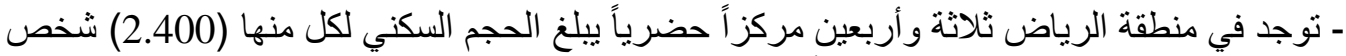

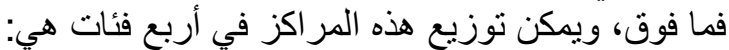

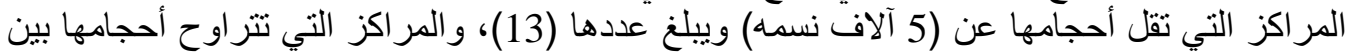

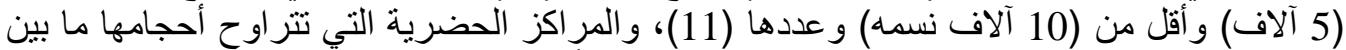

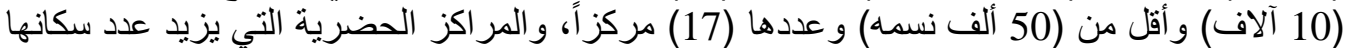

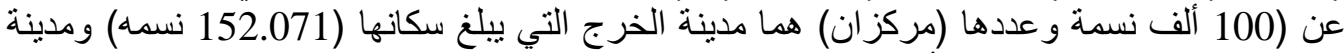
الرياض الني يزيد سكانها عن (أربعة ملايين نسمه). [1:

- يمثل مجموع سكان هذه المر اكز الحضرية حوالي (82\%) من إجمالي سكان المملكة القاطنين في

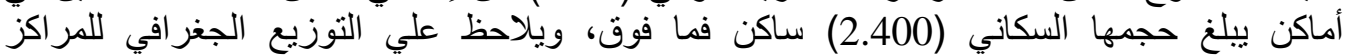

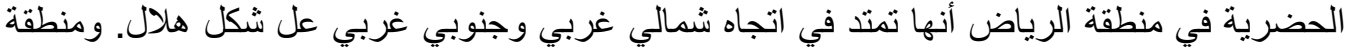

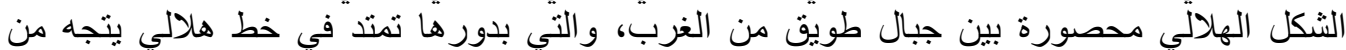

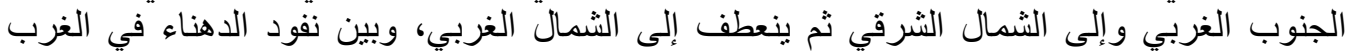

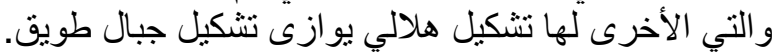

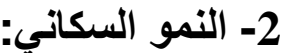

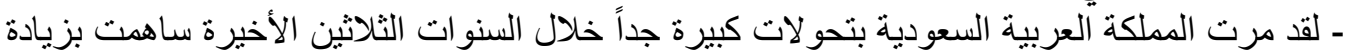

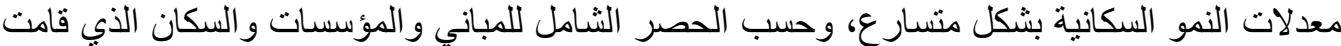

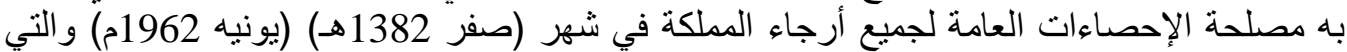
تعتبر إحصائية أولية غير دقيقة كان عدد سكان المملكة العربية السعودية (3.243.910) نسمه منهم

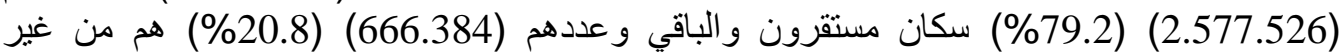

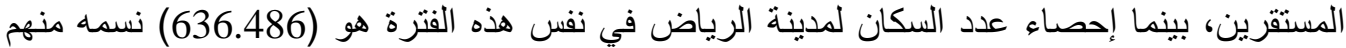
(415.148) (81.1\%) سكان مستقرون بالمدينة والباقون و عددهم (96.794) (18.9\%) هم من غير البرن 


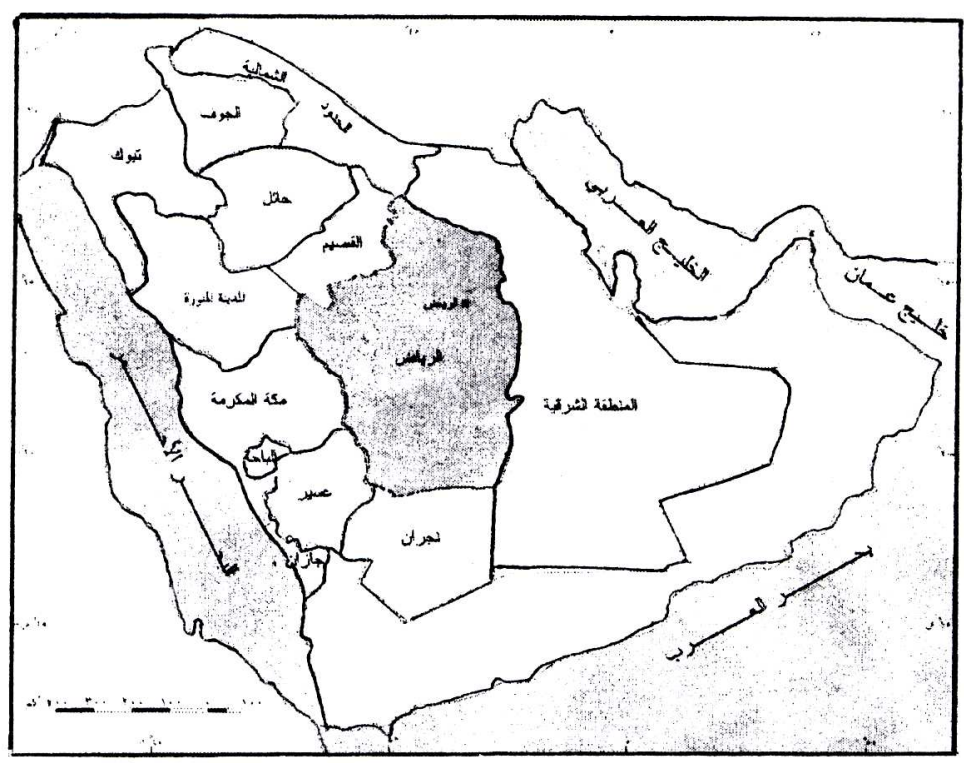

شكل رقم (1): خريطة توضح حدود منطقة الرياض وحدود المناطق الإدارية بالمملكة العربية السعودية.

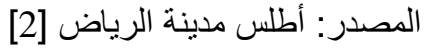

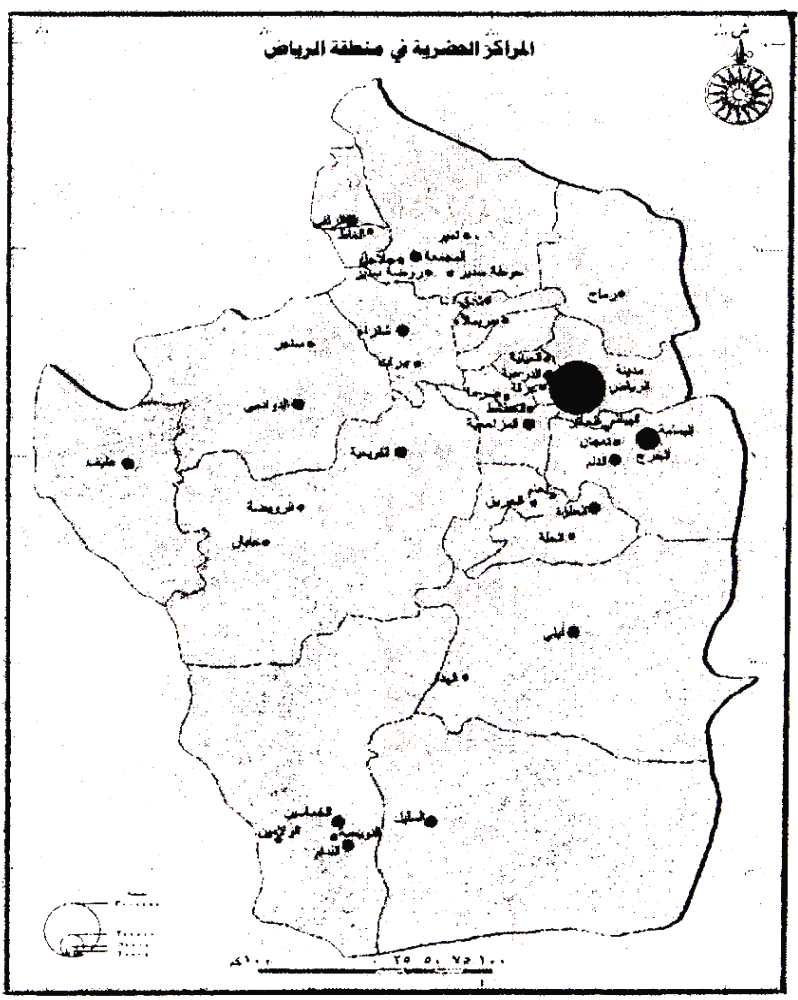

شكل رقم (2): خريطة نوضح المر اكز الحضرية في منطقة الرياض بالمملكة العربية السعودية.

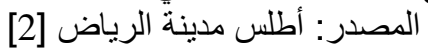




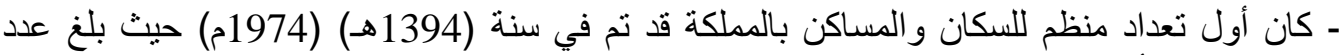

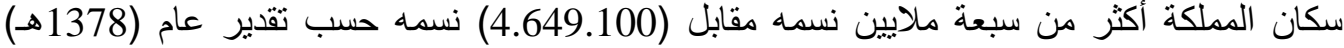

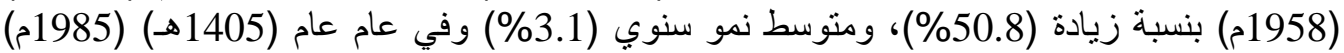

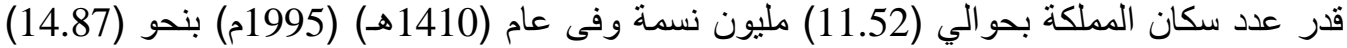

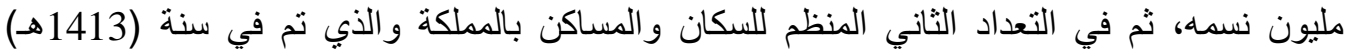

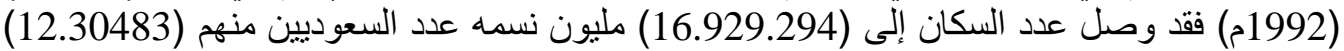
نسمة ويرجع ارتفاع عدد سكان المملكة السعوديين إلى ارتفاع نسبة المو اليد حيث زليث زادت على اللى (42) في

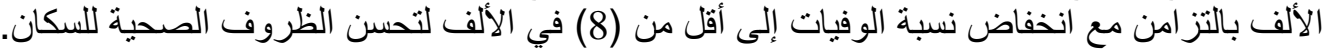

\section{* وتوجد عدة عوامل لزيادة معدلات النمو السكاني [5] مثل:}

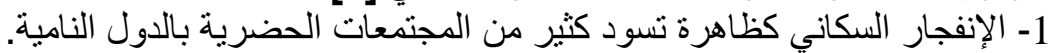

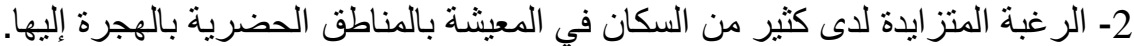

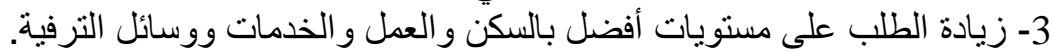
4- تغيير النمط المعيشى بتز ايد الإستهلاك. بالك.

- ركزت خطط التنمية الخمسية في بعض جو انبها على دعم التوازن بتنمية المدن الصغيرة والمتوسطة

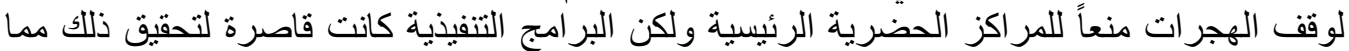

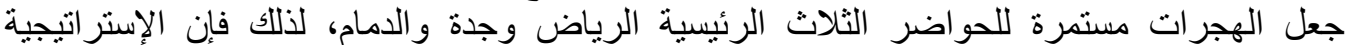

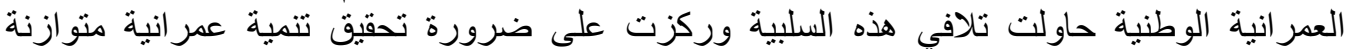

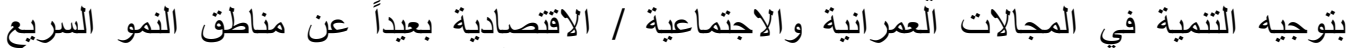

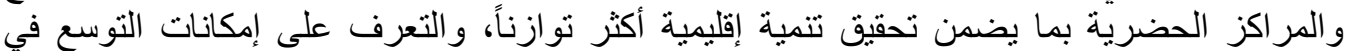

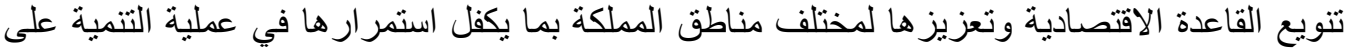

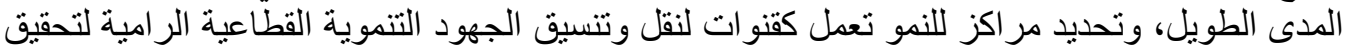

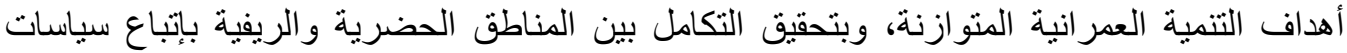

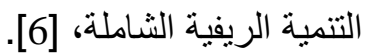

\section{1-2 النمو السكاني لمدينة الرياض:}

ـ ازداد عدد سكان مدينة الرياض بشكل كبير خلال العقود القليلة الماضية، فكما يظهر في الجدول رقم

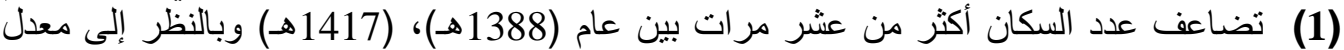

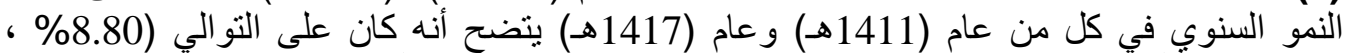

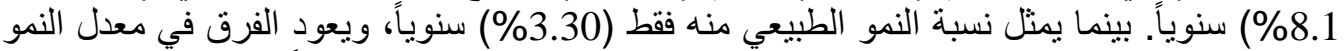
السنوي إلى النمو من الهجرة، حيث بلغ في عام (1411هـ) (5.50\%) سنوياً وفي عام (1417هـ)

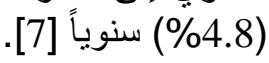

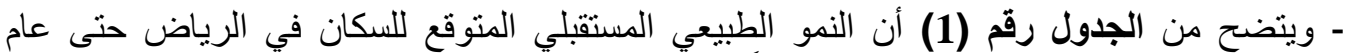

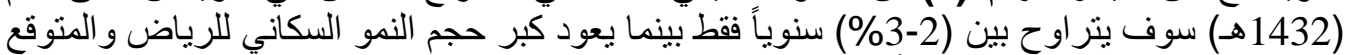

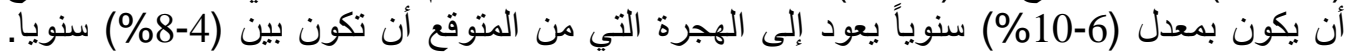

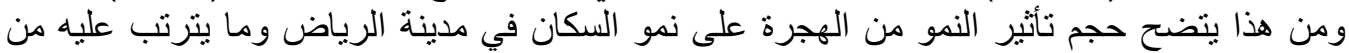

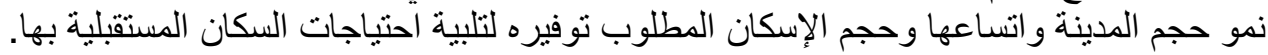


جدول رقم (1): عدد سكان مدينة الرياض تاريخياً.

\begin{tabular}{|c|c|c|c|c|c|c|c|}
\hline السعوديبين & السعوديين & السعوديين & المجموع & النمو من & الطبيعي & النوي النوي & الهجري \\
\hline- & - & - & 300 & - & - & - & 1388 \\
\hline- & - & - & 690 & - & - & - & 1397 \\
\hline$\% 61$ & 543 & 845 & 1389 & - & - & - & 1407 \\
\hline$\% 66$ & 752 & 1331 & 2004 & $\% 5.50$ & $\% 3.30$ & $\% 8.80$ & 1411 \\
\hline$\% 68$ & 1000 & 2100 & 3100 & $\% 4.80$ & $\% 3.30$ & $\% 8.10$ & 1417 \\
\hline$\% 74$ & 1200 & 3500 & 4700 & $\% 7.90$ & $\% 2.10$ & $\% 10.0$ & 1422 \\
\hline$\% 77$ & 1400 & 4700 & 6100 & $\% 4.50$ & $\% 2.90$ & $\% 7.40$ & 1427 \\
\hline$\% 79$ & 1600 & 6100 & 7700 & $\% 3.90$ & $\% 2.00$ & $\% 5.90$ & 1432 \\
\hline
\end{tabular}

المصدر: الهيئة العليا لتطوير مدينة الرياض [7 [7

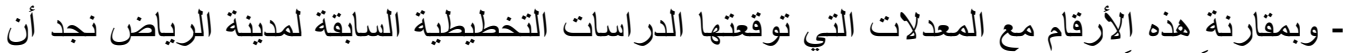

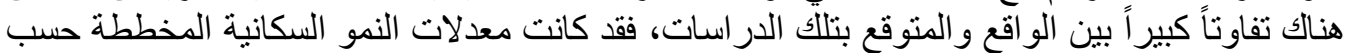

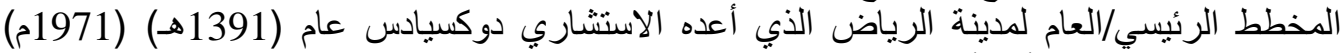

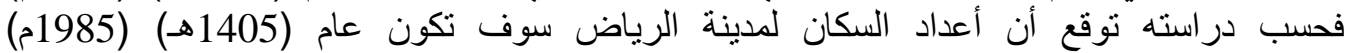

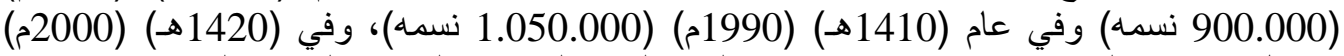

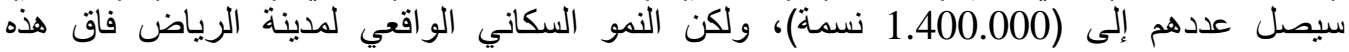

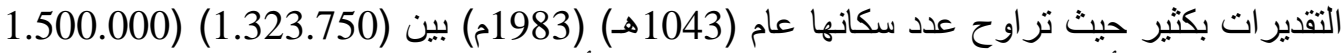

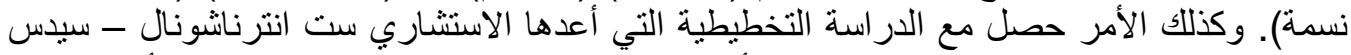

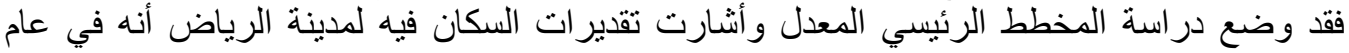

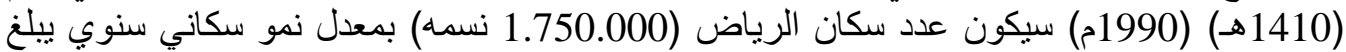
(3\%) للسعوديين، أما في عام (1420هـ) (2000م) فتوقع أن يصل عدد سكانها إلى نحو (2.5 مليون

نسمه) [8]

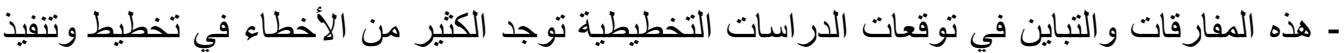

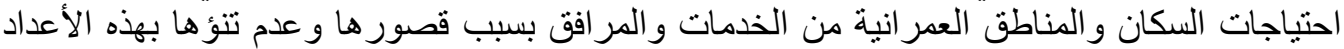

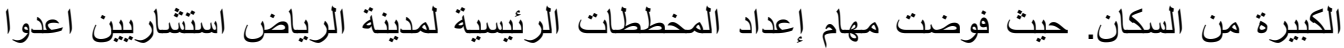

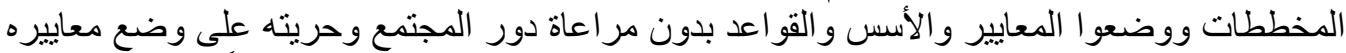

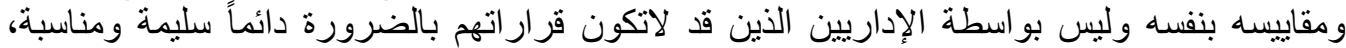

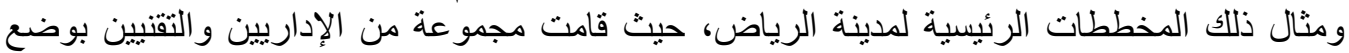

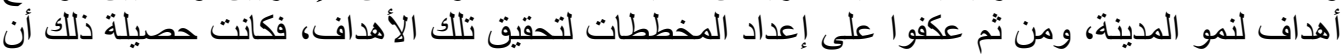

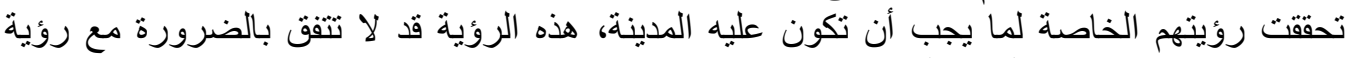
واحتياجات ورغبات وتطلعات المجتمع نفسه [9].

1-1-2 أسباب النمو السكاني في مدينة الرياض:

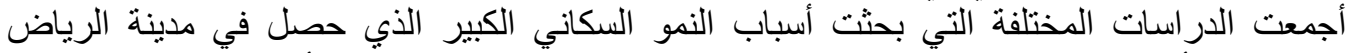

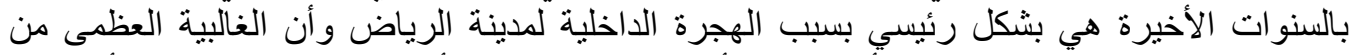

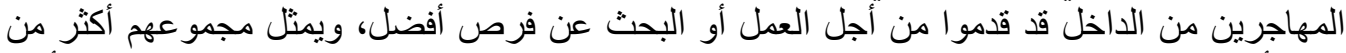

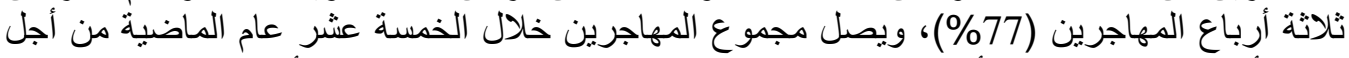
العمل أو البحث عن فرص أفضل إلى (78.5\%). وكان الالتحاق بالمدارس من أجل إكمال الدراسة هو الدا 
السبب الثاني بعد البحث عن فرص عمل أفضل، حيث شكل المهاجرون من أجل الدراسة بشقيها

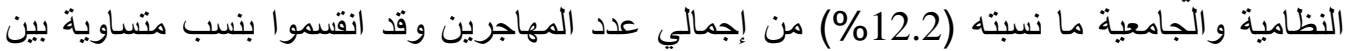

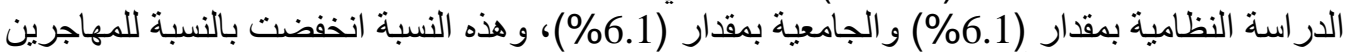

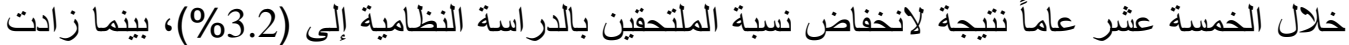

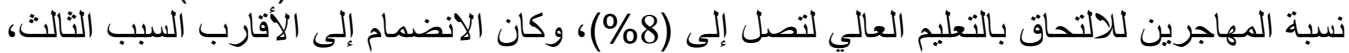

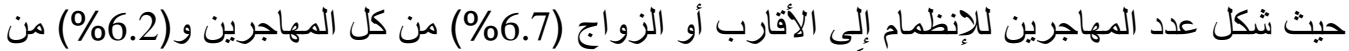

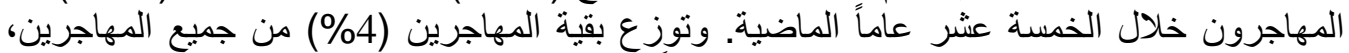

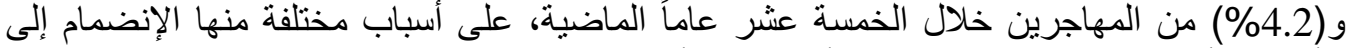

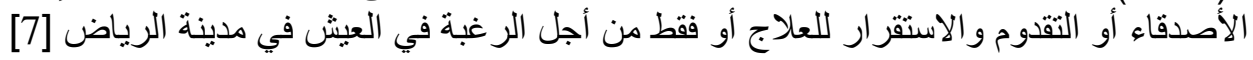

جدول رقم (2): أسباب الهجرة الداخلية إلى الرياض 1417هز

\begin{tabular}{|c|c|c|c|c|c|c|}
\hline التزتيب & النسبة & خلال 15 عام & الترتيب & النسبة & المهاجرين & سبب الهجرة \\
\hline 1 & $\% 74.7$ & 53390 & 1 & $\% 72.6$ & 133404 & 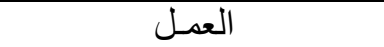 \\
\hline 5 & $\% 3.2$ & 2283 & 4 & $\% 6.1$ & 11122 & الدر اسـة النظامية \\
\hline 2 & $\% 8$ & 5712 & 3 & $\% 6.2$ & 11198 & الدر اسة الجامعية \\
\hline 3 & $\% 6.2$ & 4442 & 2 & $\% 6.7$ & 12353 & الإنضمام للأقارب أو الزواج \\
\hline 9 & $\% 0.4$ & 272 & 9 & $\% 0.2$ & 383 & الإنضمام للأصدقاء \\
\hline 8 & $\% 0.5$ & 359 & 8 & $\% 0.6$ & 1150 & صحي علاج \\
\hline 4 & $\% 3.8$ & 2691 & 5 & $\% 4.4$ & 8121 & البحث عن فرص أفضل \\
\hline 6 & $\% 1.7$ & 1228 & 7 & $\% 1.5$ & 2807 & حب العيش في الرياض \\
\hline 7 & $\% 1.5$ & 1131 & 6 & $\% 1.7$ & 3139 & أخــرى \\
\hline- & - & 71508 & - & - & 183677 & المجموع \\
\hline
\end{tabular}

المصدر: الهيئة العليا لتطوير مدينة الرياض [7]

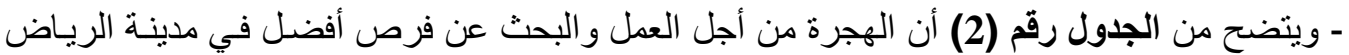

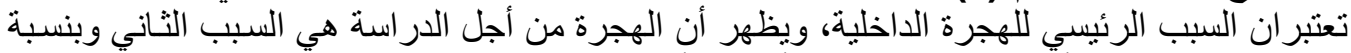

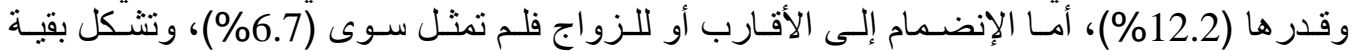

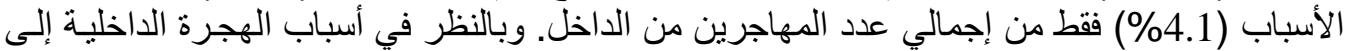

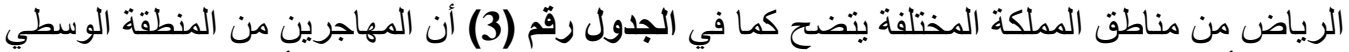

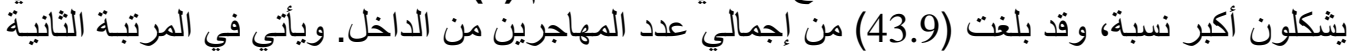

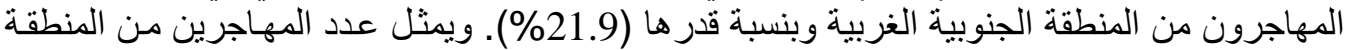

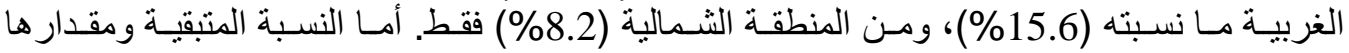

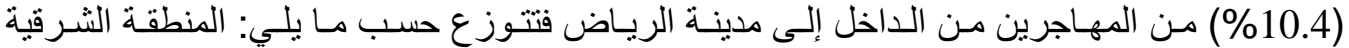

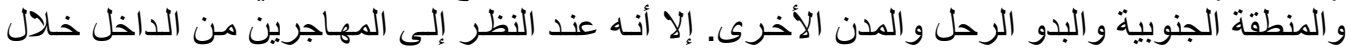

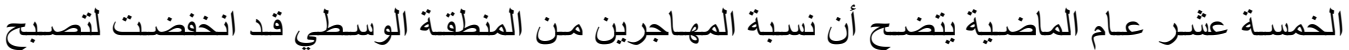

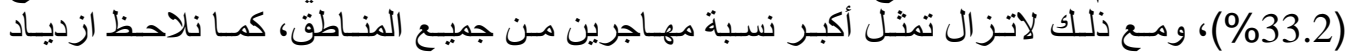

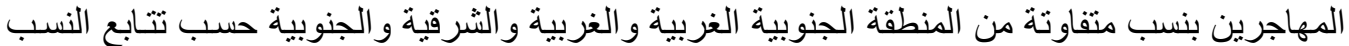

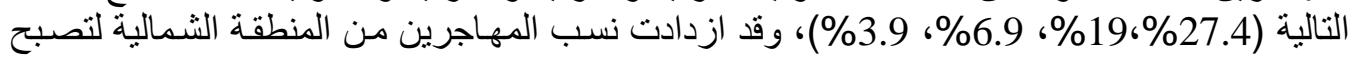

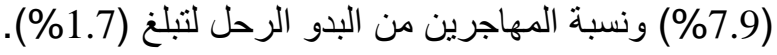




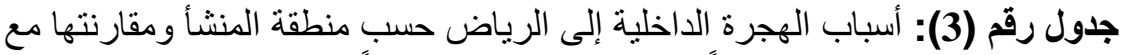

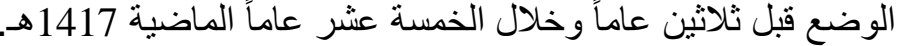

\begin{tabular}{|c|c|c|c|c|c|c|c|}
\hline خلال 15 عهاجرين & و المهاجرين & \multicolumn{5}{|c|}{ جميـع المهاجرين } & \\
\hline المجموع & المجموع & المجموع & أخرى & وزأ أقارب & دراسة & وفرصل عمل & منطقة \\
\hline $\begin{array}{l}23773 \\
\% 33.2\end{array}$ & $\begin{array}{l}109897 \\
\% 63.2\end{array}$ & $\begin{array}{l}80557 \\
\% 100 \\
\% 43.9\end{array}$ & $\begin{array}{l}3477 \\
\% 4.3 \\
\% 1.9 \\
\end{array}$ & $\begin{array}{l}5892 \\
\% 7.3 \\
\% 3.2 \\
\end{array}$ & $\begin{array}{c}13538 \\
\% 16.8 \\
\% 7.4\end{array}$ & $\begin{array}{l}57650 \\
\% 71.6 \\
\% 31.4\end{array}$ & $b$ \\
\hline $\begin{array}{l}2757 \\
\% 3.9\end{array}$ & $\begin{array}{l}1240 \\
\% 1.0\end{array}$ & $\begin{array}{c}6964 \\
\% 100 \\
\% 3.8\end{array}$ & $\begin{array}{c}74 \\
\% 1.10 \\
\% \text { صفر }\end{array}$ & $\begin{array}{c}256 \\
\% 3.7 \\
\% 0.1\end{array}$ & $\begin{array}{c}247 \\
\% 3.5 \\
\% 0.1\end{array}$ & $\begin{array}{c}6387 \\
\% 91.7 \\
\% 3.5\end{array}$ & الجنوبي \\
\hline $\begin{array}{l}5643 \\
\% 7.9\end{array}$ & $\begin{array}{l}3387 \\
\% 2.7\end{array}$ & $\begin{array}{l}14998 \\
\% 100 \\
\% 8.2\end{array}$ & $\begin{array}{c}375 \\
\% 2.5 \\
\% 0.2\end{array}$ & $\begin{array}{l}1029 \\
\% 6.9 \\
\% 0.6\end{array}$ & $\begin{array}{l}2014 \\
13.43 \\
\% 1.6\end{array}$ & $\begin{array}{c}11580 \\
\% 77.2 \\
\% 6.3\end{array}$ & الشمالية \\
\hline $\begin{array}{c}13610 \\
\% 19\end{array}$ & $\begin{array}{l}28668 \\
\% 4.1\end{array}$ & $\begin{array}{l}28668 \\
\% 100 \\
\% 15.6\end{array}$ & $\begin{array}{l}1595 \\
\% 5.6 \\
\% 0.9\end{array}$ & $\begin{array}{l}2135 \\
\% 7.4 \\
\% 1.2\end{array}$ & $\begin{array}{c}2993 \\
\% 10.4 \\
\% 1.6\end{array}$ & $\begin{array}{l}21945 \\
\% 76.5 \\
\% 11.9\end{array}$ & الغزبية \\
\hline $\begin{array}{l}19592 \\
\% 27.4\end{array}$ & 6223 & $\begin{array}{l}40177 \\
\% 100 \\
\% 21.9\end{array}$ & $\begin{array}{l}1171 \\
\% 2.9 \\
\% 0.6\end{array}$ & $\begin{array}{l}1516 \\
\% 3.8 \\
\% 0.8\end{array}$ & $\begin{array}{l}2246 \\
\% 5.9 \\
\% 1.2\end{array}$ & $\begin{array}{l}35246 \\
\% 87.7 \\
\% 19.2\end{array}$ & الجنوبية الغية \\
\hline $\begin{array}{c}4907 \\
6.9\end{array}$ & $\% 0.6$ & $\begin{array}{l}8298 \\
\% 100 \\
\% 4.5\end{array}$ & $\begin{array}{c}611 \\
\% 7.4 \\
\% 0.1\end{array}$ & $\begin{array}{c}1345 \\
\% 16.2 \\
\% 0.7\end{array}$ & $\begin{array}{c}1001 \\
\% 12.6 \\
\% 0.5\end{array}$ & $\begin{array}{c}5341 \\
\% 64.4 \\
\% 2.9\end{array}$ & الشرقية \\
\hline $\begin{array}{l}1192 \\
\% 1.7\end{array}$ & $\begin{array}{c}906 \\
\% 0.7\end{array}$ & $\begin{array}{c}3721 \\
\% 100 \\
\% 2.0\end{array}$ & $\begin{array}{c}176 \\
\% 4.7 \\
\% \text { صفر }\end{array}$ & $\begin{array}{c}180 \\
\% 4.8 \\
\% 0.1\end{array}$ & $\begin{array}{c}152 \\
\% 4.1 \\
\% 0.1\end{array}$ & $\begin{array}{c}3213 \\
\% 86.3 \\
\% 1.7\end{array}$ & بدو رحل \\
\hline $\begin{array}{r}34 \\
\text { صفر \% }\end{array}$ & $\% 0.1$ & $\begin{array}{c}292 \\
\% 100 \\
\% 0.2\end{array}$ & صفر صفر\% & صفر صفر\% & $\begin{array}{c}129 \\
\% 44.2 \\
\% 0.1\end{array}$ & $\begin{array}{c}163 \\
\% 55.8 \\
\% 0.1\end{array}$ & أخرى مدينة \\
\hline 71508 & 127701 & $\begin{array}{c}183677 \\
\% 100\end{array}$ & $\begin{array}{l}7479 \\
\% 4.1\end{array}$ & $\begin{array}{l}12353 \\
\% 6.7\end{array}$ & $\begin{array}{l}22320 \\
\% 12.2\end{array}$ & $\begin{array}{c}141525 \\
\% 77.1\end{array}$ & المجموع \\
\hline
\end{tabular}

المصدر: الهيئة العليا لتطوير مدينة الرياض [77.

- وبالنظر في جدول رقم (3) نجد أن نسب المهاجرين حسب سبب الهجرة لكل منطقة، يتضح أن أن أكبر

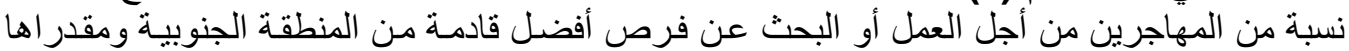

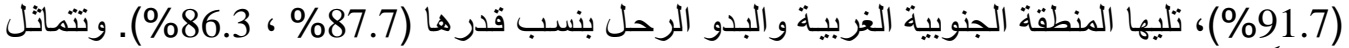

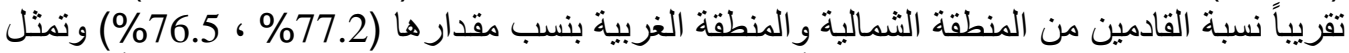
المنطقة الوسطى ما نسبته (71.6\%)، وتأتي بعد ذللك المنطقة الثرقية بنسبة مهاجرين للعمل أو البحث 
عن فرص أفضل وقدرها (64.4\%) من إجمالي المهاجرين من المنطقة، ثم بقيـة المدن الأخرى بنسبة وقدر ها (55.8\%).

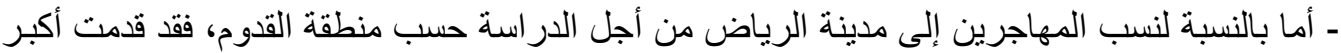

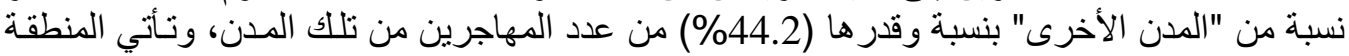

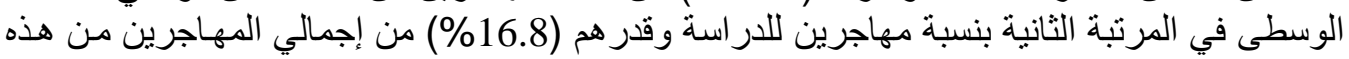

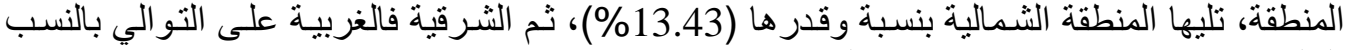
التالية (12.6\%، 10.4\%) من عدد المهاجرين منها.

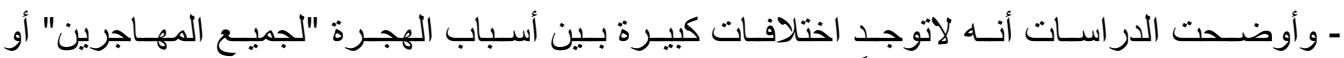

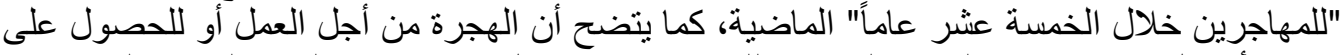

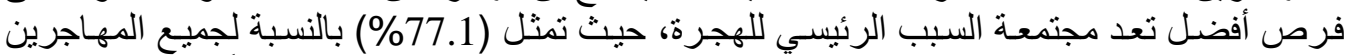

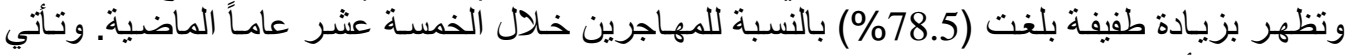

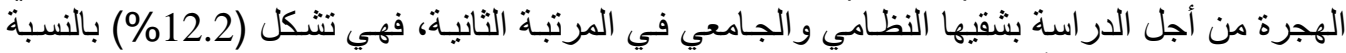

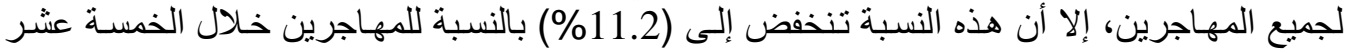

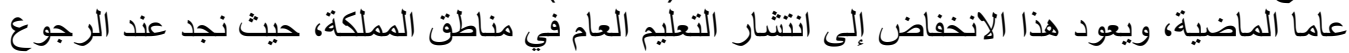

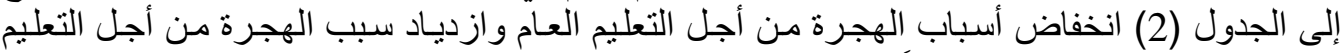
الجامعي خلال الخمسة عشر عاماً الماضية [7].

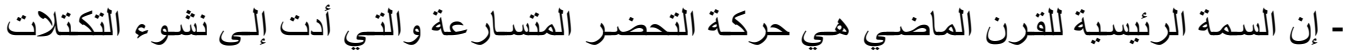

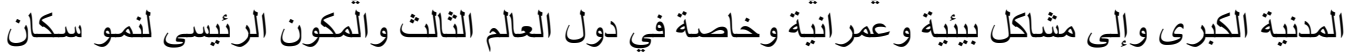

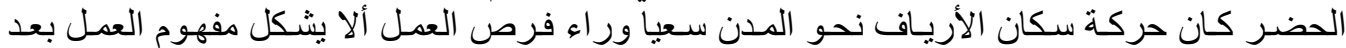

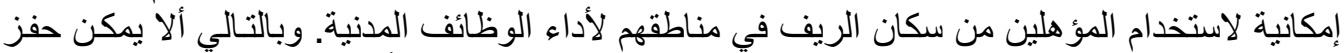

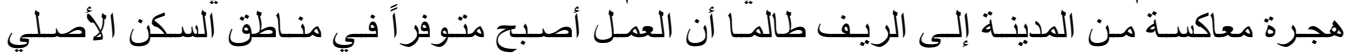

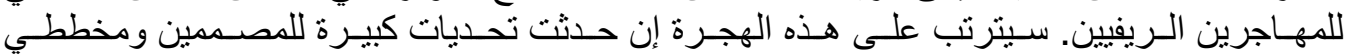
استعمالات الأرض في المدن كما ترتب من تحديات خلال الهجرة من الريف إلى المدينة [10].

\section{3- المقومات البيئية في مدينة الرياض: البئة البينة}

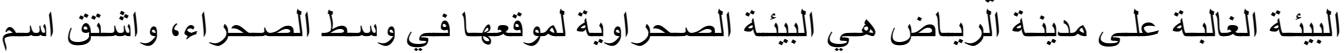

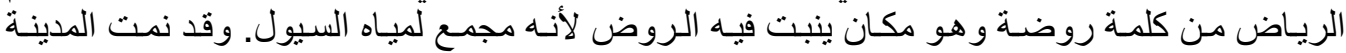

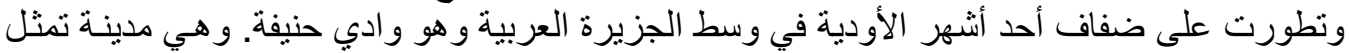

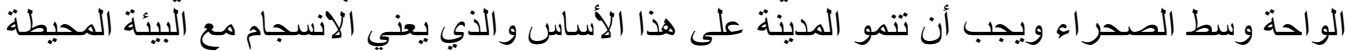

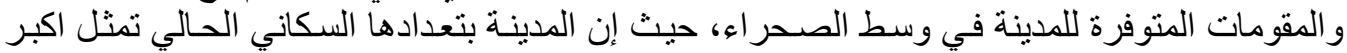

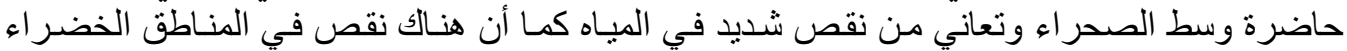

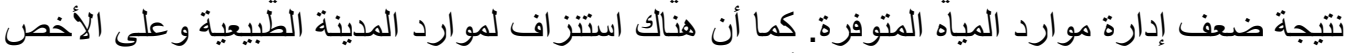

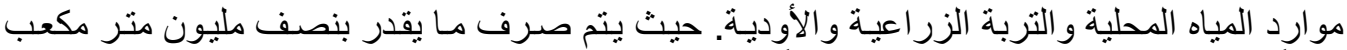

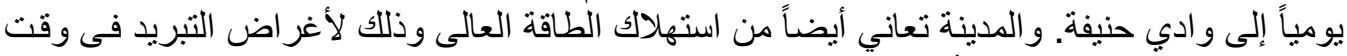

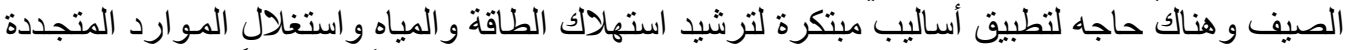

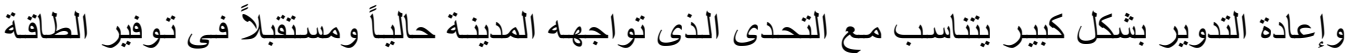
و والمياه.

\section{1-3 مظاهر السطح}

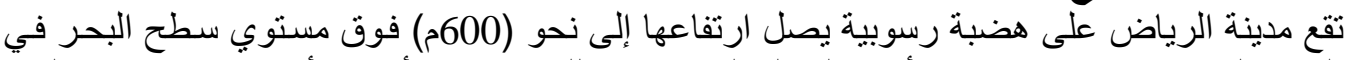

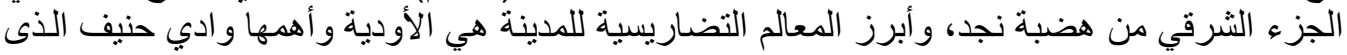




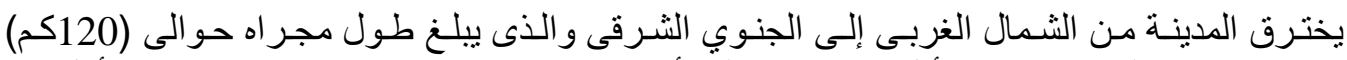

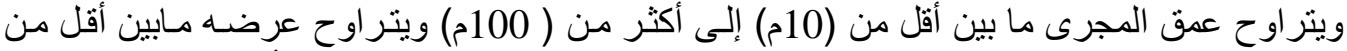

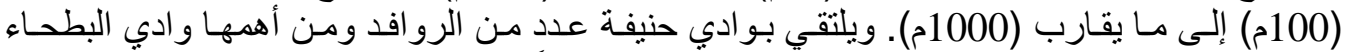

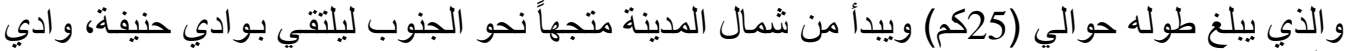

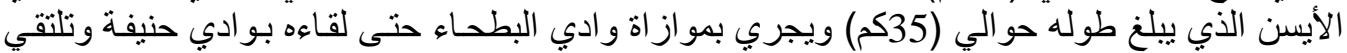

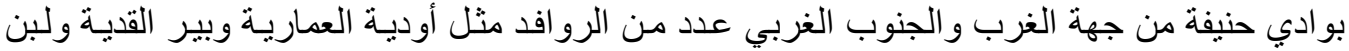
ونمار.

- عند هضبة نجد الكبرى غرباً سلسلة جبال طويق وحز ام صحر اء الدهناء على حافتها الثرقية وتنحدر

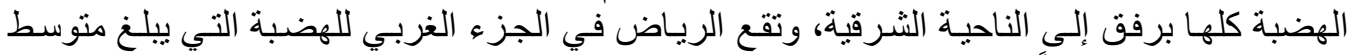

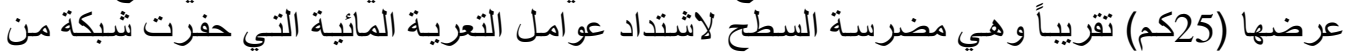
الأودية العميقة بها.

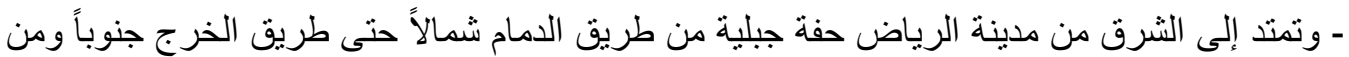

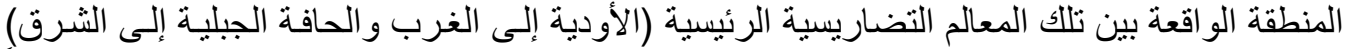

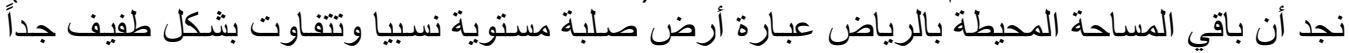

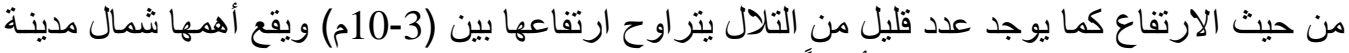

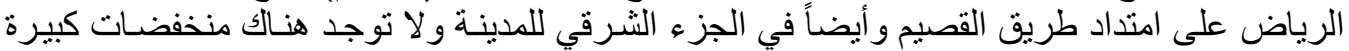
باستثناء الأودية ورو افدها.

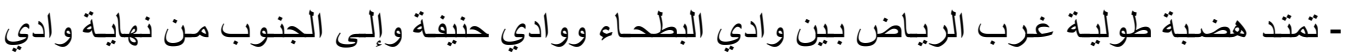

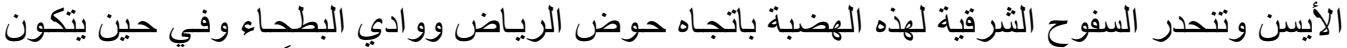

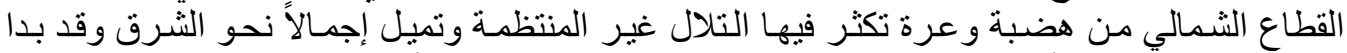

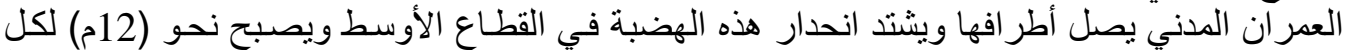

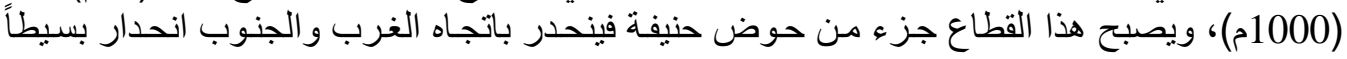

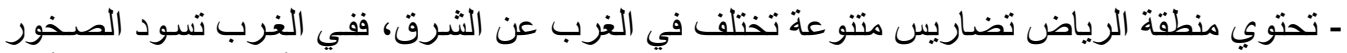

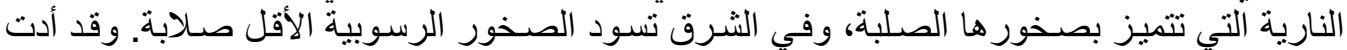

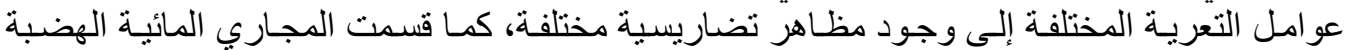

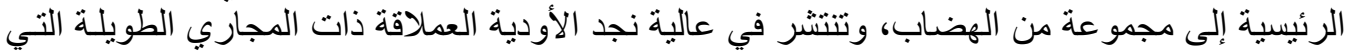

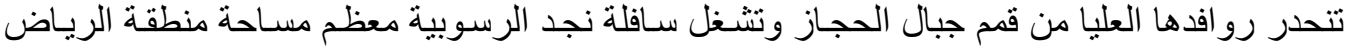

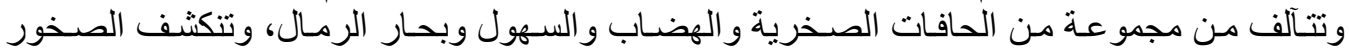

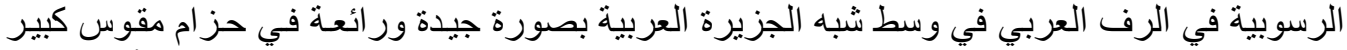

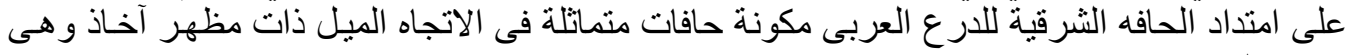

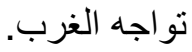

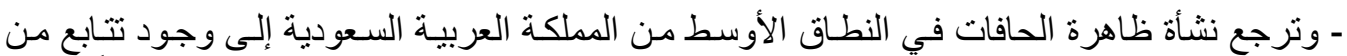

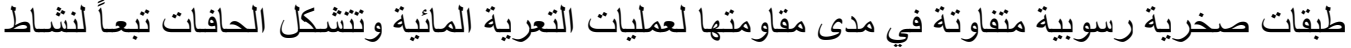

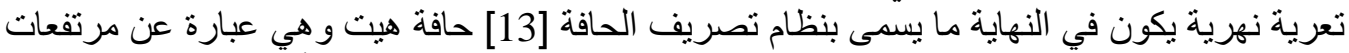

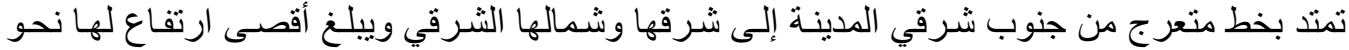

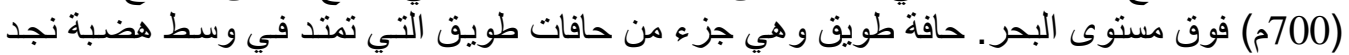

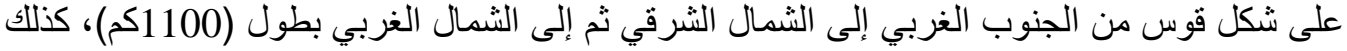

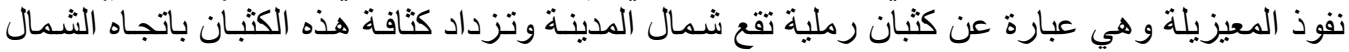
حيث تصل برمال بنبان. 


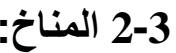

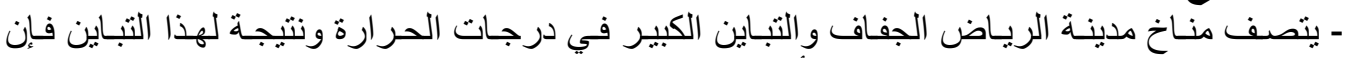

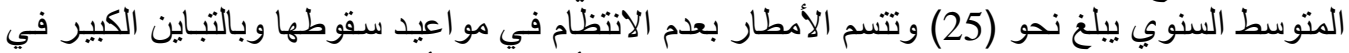

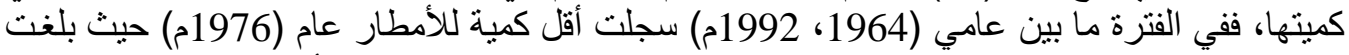

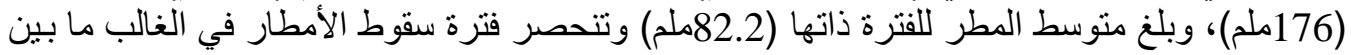

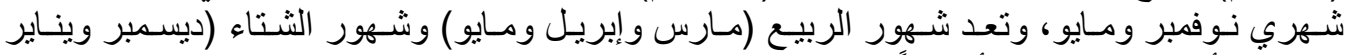
وفبر اير) أكثر شهور السنة أمطار اً.

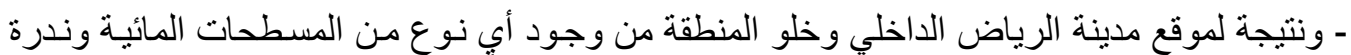

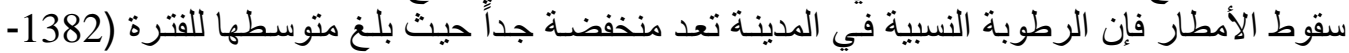

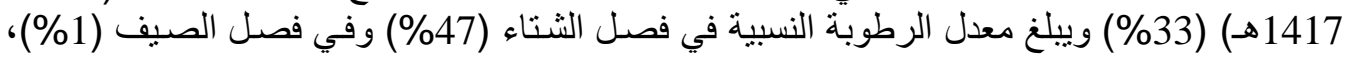

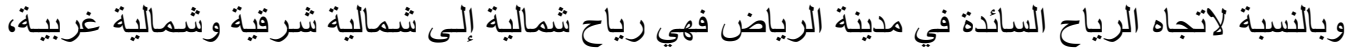

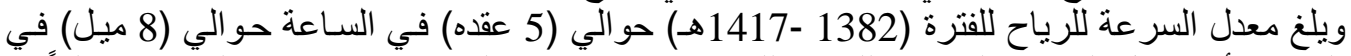

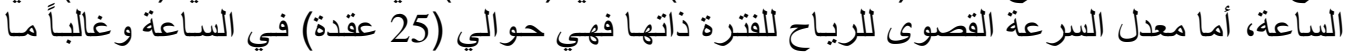

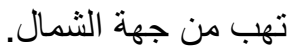

\section{3-3 إنة المصادر المائية:}

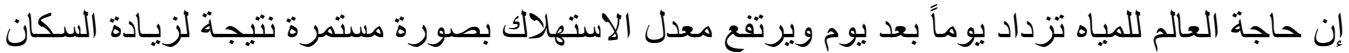

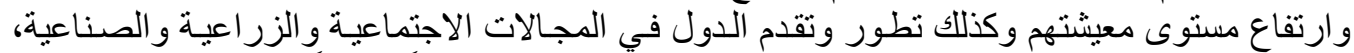

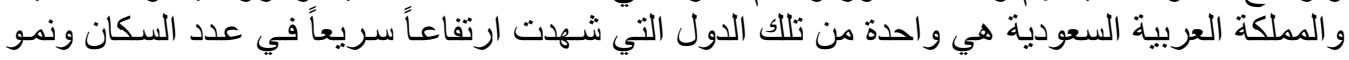

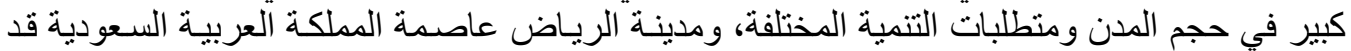

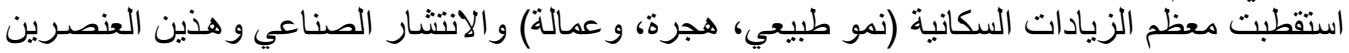

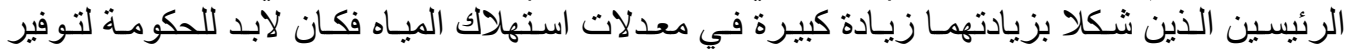

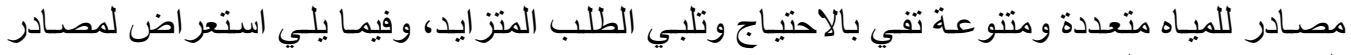
المياه في مدينة الرياض ومقدار ما توفرهة

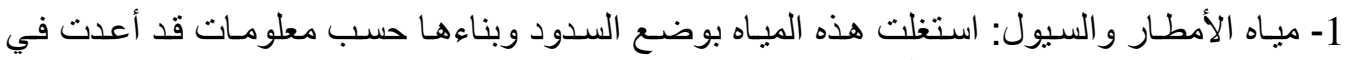
در اسات مناخية وجغر افية و هذه السدود هي:

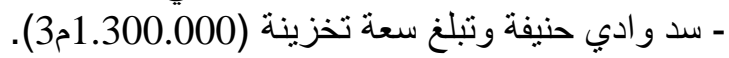

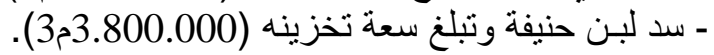
- سد غـار حنيفة وتبلغ سعة تخزينة (1.300.000م33).

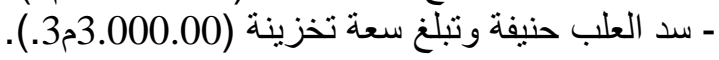

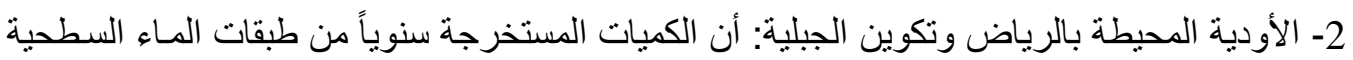

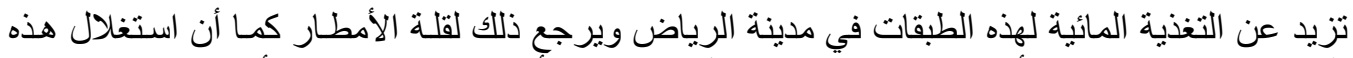

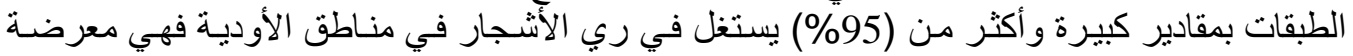
للجفاف ومن ناحية بكثيرولوجية فإن هذه المياه ملوثة.

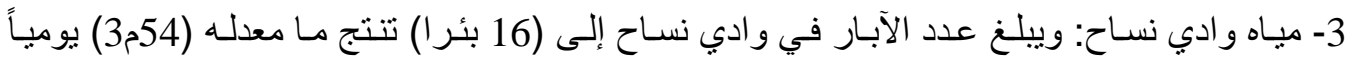

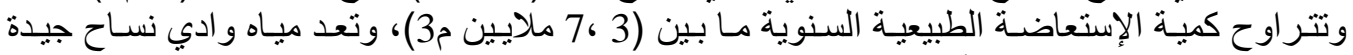

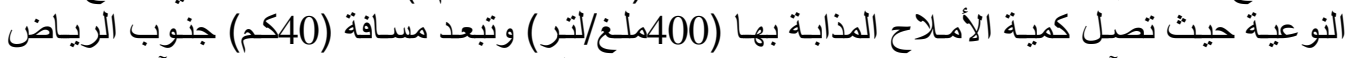

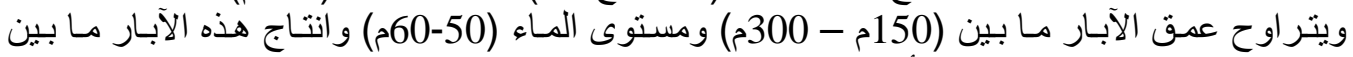

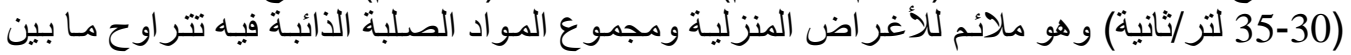

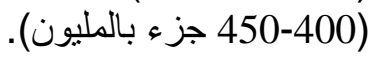




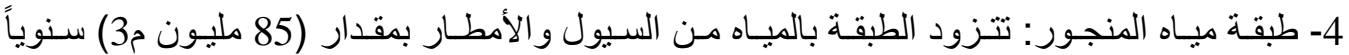

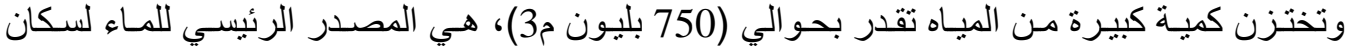

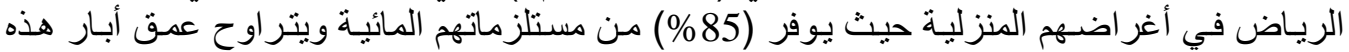

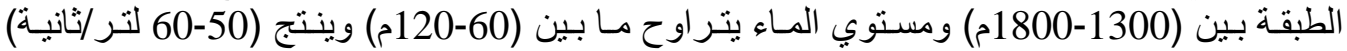

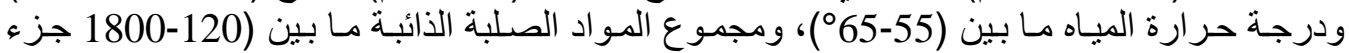

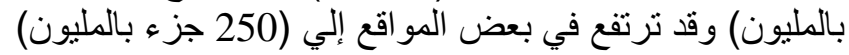

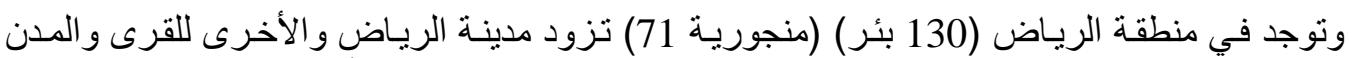

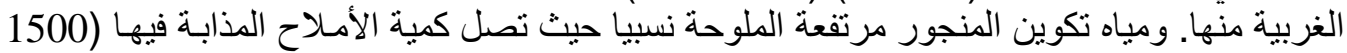

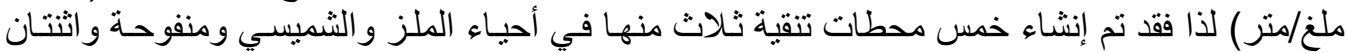

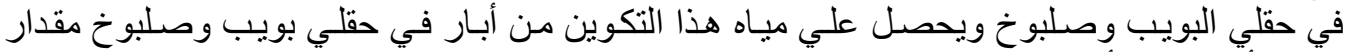
(108 ألف ، 86 ألف م3) يوميا علي التو الي.

5- مشروع مياه الوسيع: يقع علي مسافة (110كم) شرق الرياض وتنتج أبار الوسيع (62 بئرا) حو الي

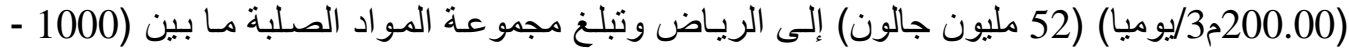

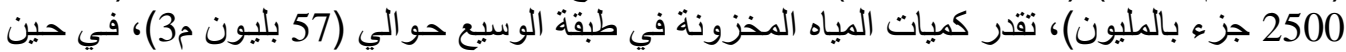

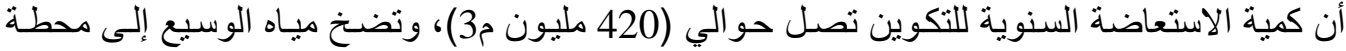
على بعد (30كم) شرقي الرياض ويتم خلطها بمياه البحر المحلاة [14].

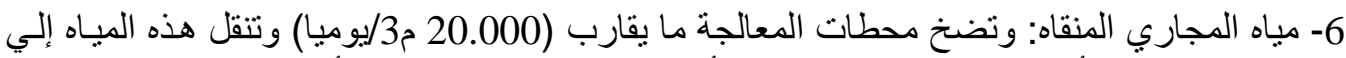

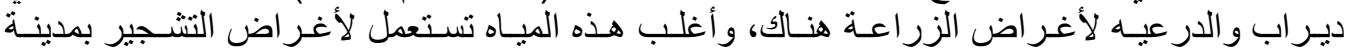

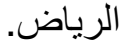

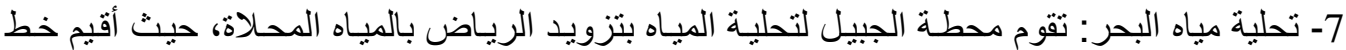

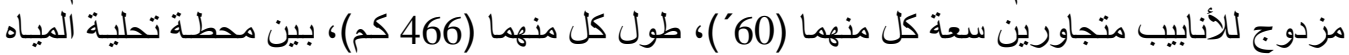

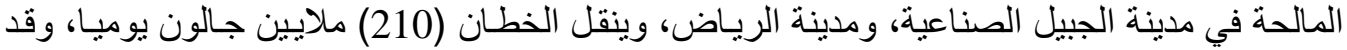
بدي بتشغيل المشروع عام (1404هـ) (1983م) [15.

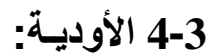
تشتهر مدينة الرياض بالعديد من الأدويـة الهامـة وقد سبق استعر اضـها بمظـاهر السطح و أهمها وادي حنيفة وو ادي البطحاء، الايسن، و أدوية العمارية وبيير والإدية والقدية لبن ونمار.

\section{1-4-3 وادي حنيفة:}

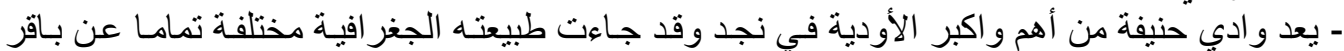

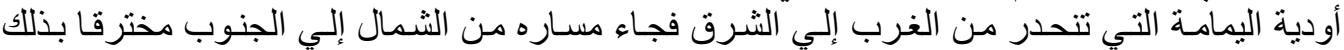

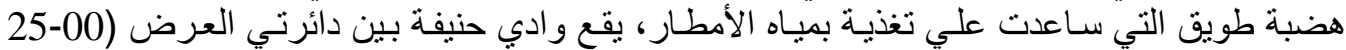

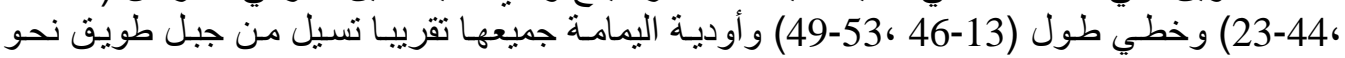

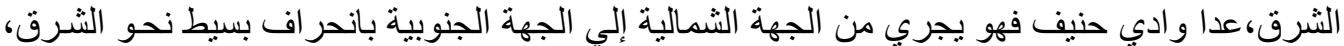

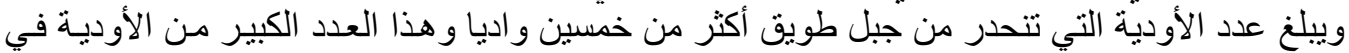

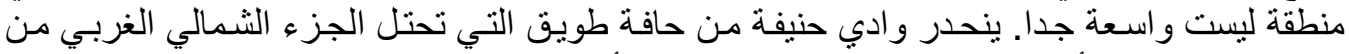

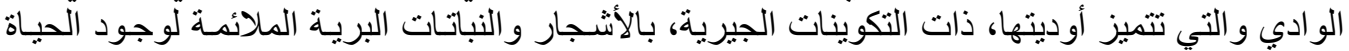

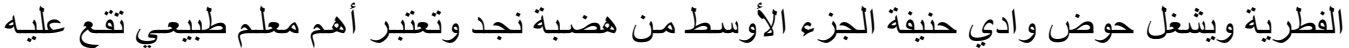




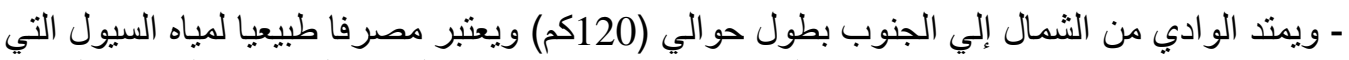

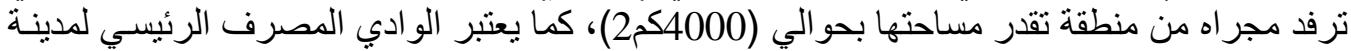

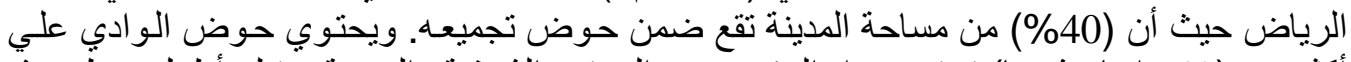

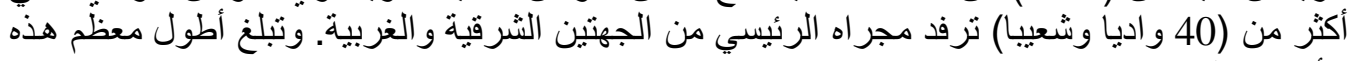
الأودية و الثنعاب نحو (25 (25م).

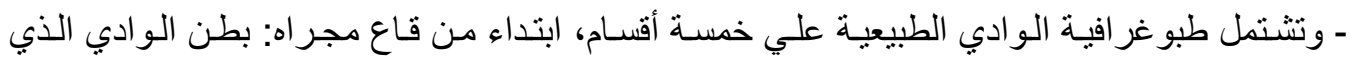

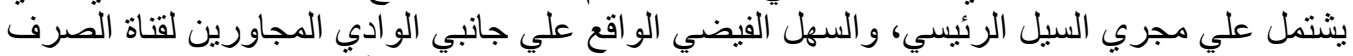

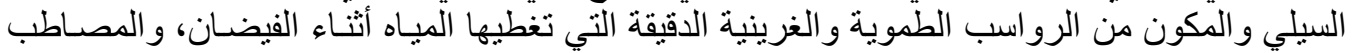

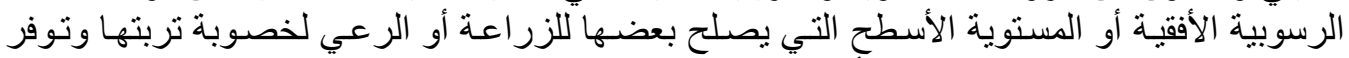

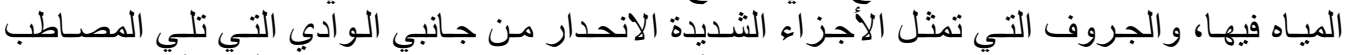

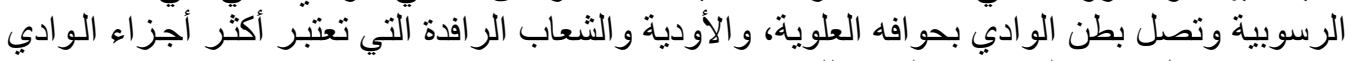

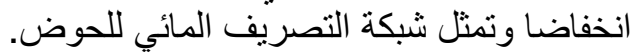

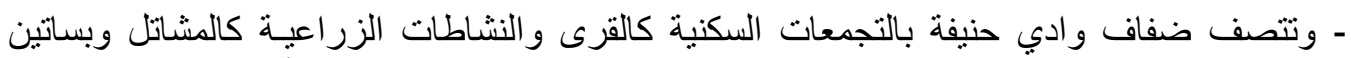

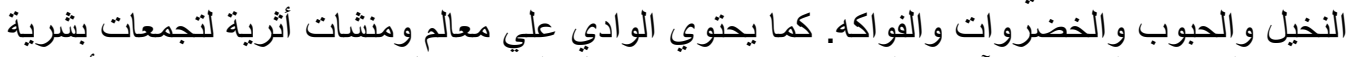

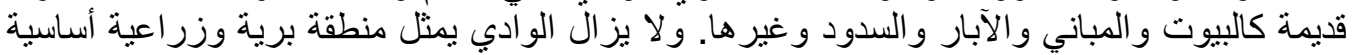

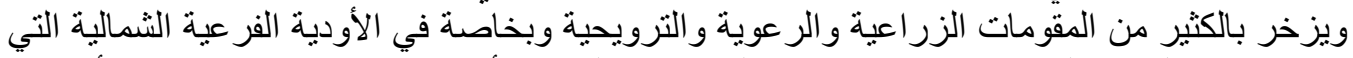

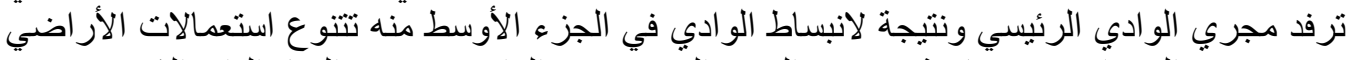

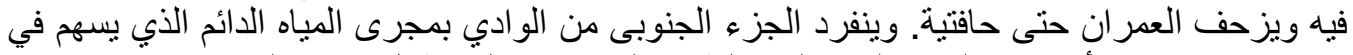

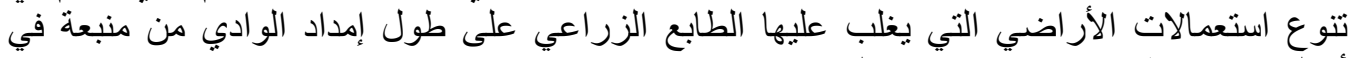
أعالي حواف طويق حتى مصبه في السهباء.

\section{4- تأثير النمو السكاني في مدينة الرياض:}

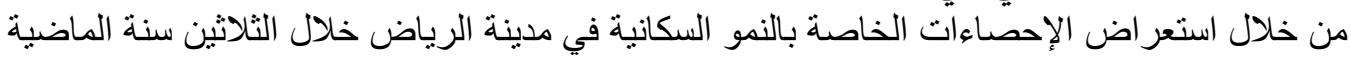

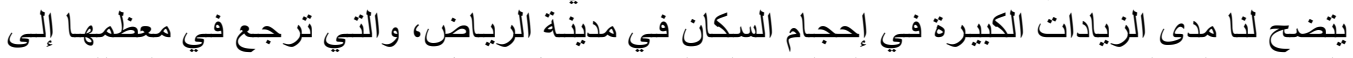

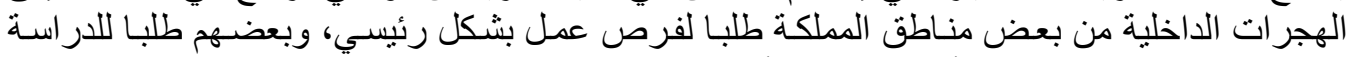

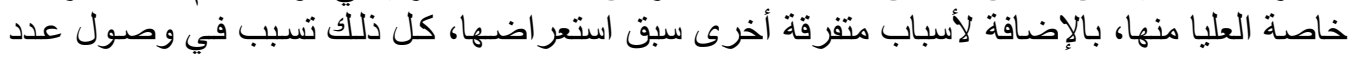

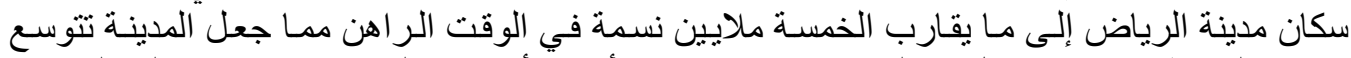

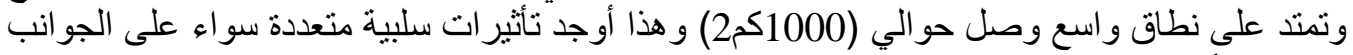
العمر انية أو على المقومات البيئية لمدينة الرياض.

\section{1-4 تأثثير النمو السكاني على الجوانب العمرانية:}

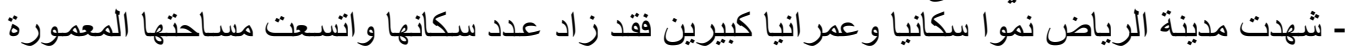

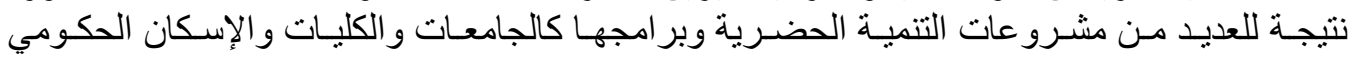

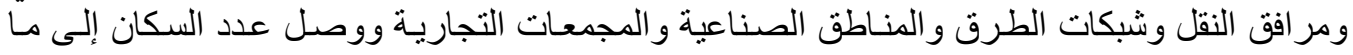

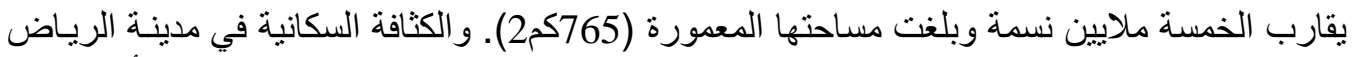

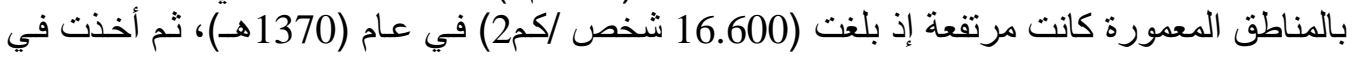

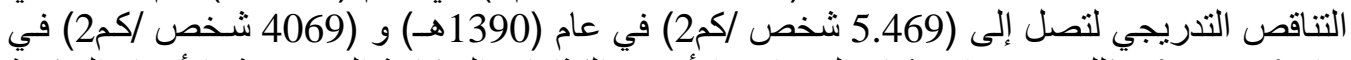

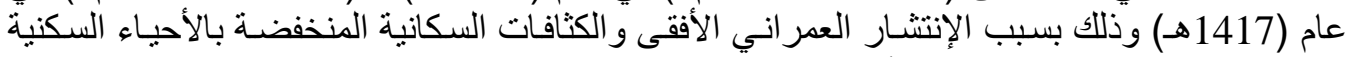

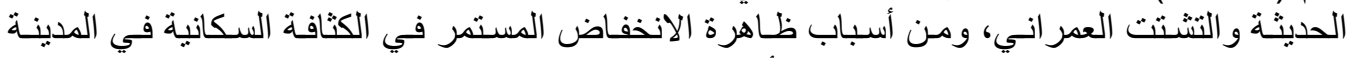

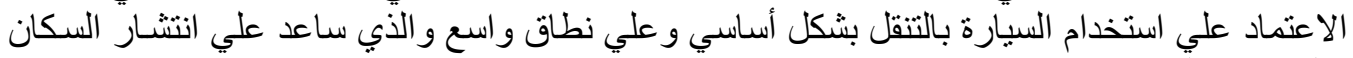
و العمر ان علي مساحات كبيرة. 


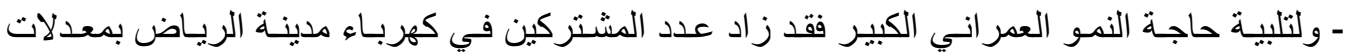

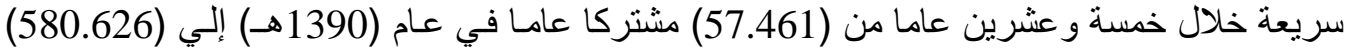

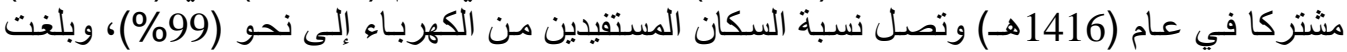
مساحة المناطق المشمولة بمر افق الكهرباء أكثر من (545كم2).

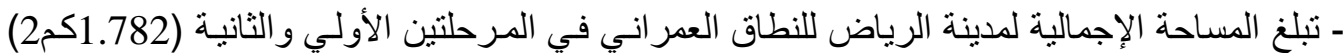

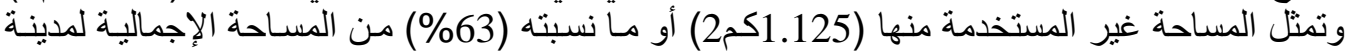

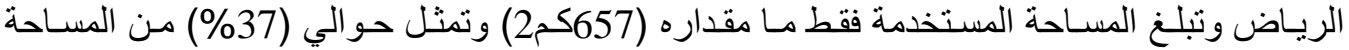

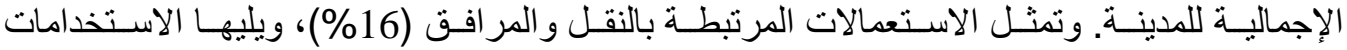

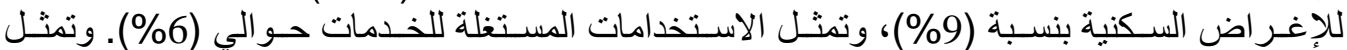

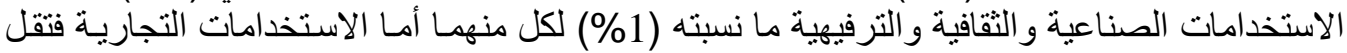

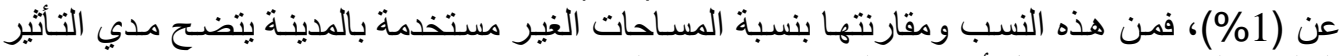
السلبي علي خطة استغلال أر اضي المدينة بكفاءة وفعالية [2].

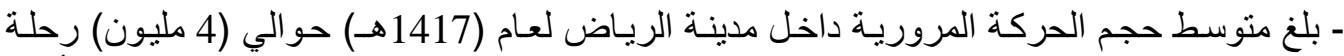

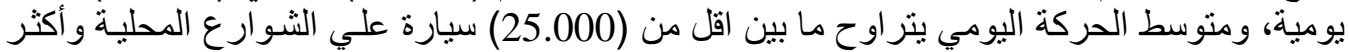

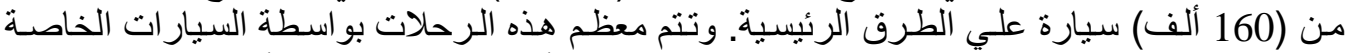

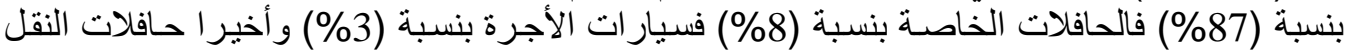

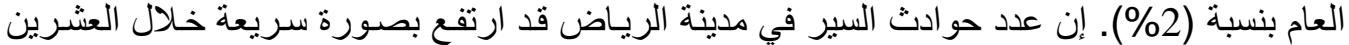

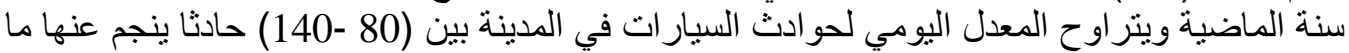

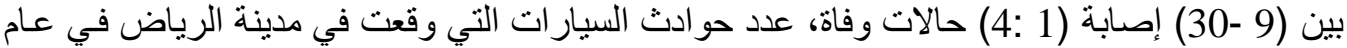

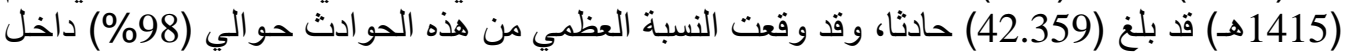

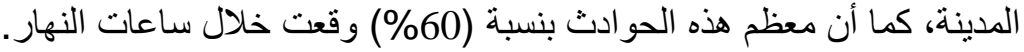

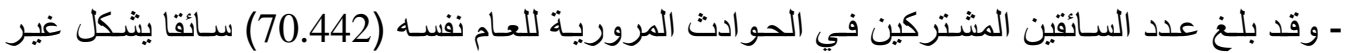

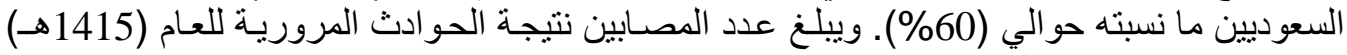
(2.330) مصابا وعدد المتوفين (365) شخصا.

\section{2-4 تأثير النمو السكاني علي المقومات البينية:}

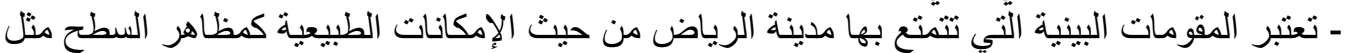

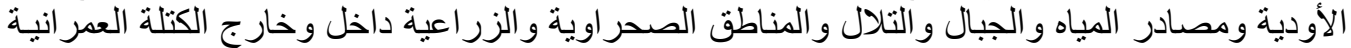

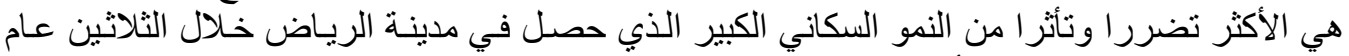

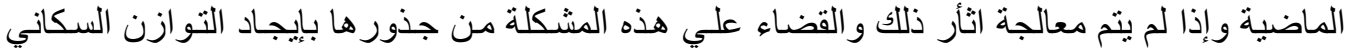

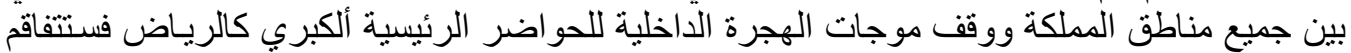
الششكلة إلي حذ يصعب معالجته، ومدي تأثر المقومات البينية التي تتمتع بها المدينة.

\section{1-2-4 التأثير على مظاهر السطح:}

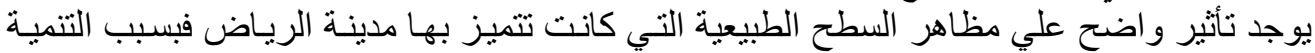

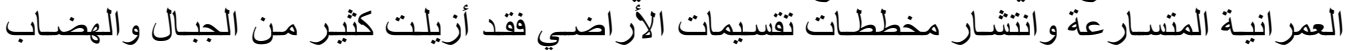

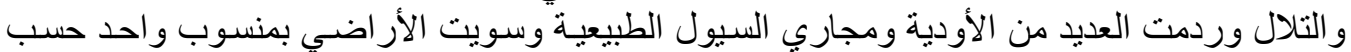

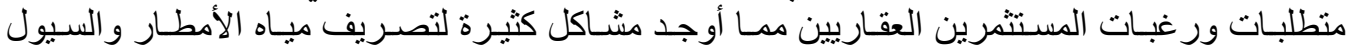

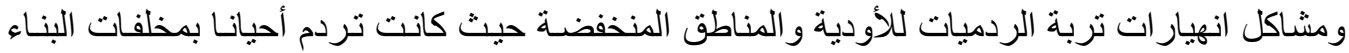


2-2-4 - 2-4 التأثير علي المناخ:

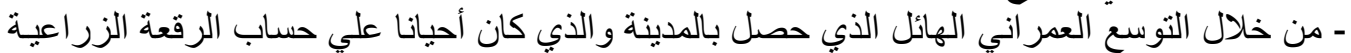

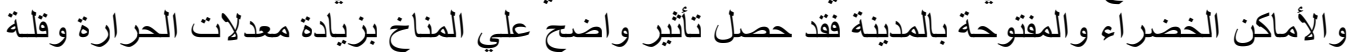

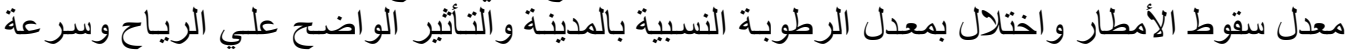

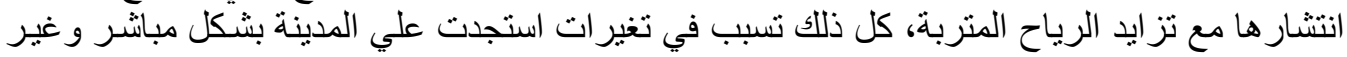
مبانثر.

\section{3-2-4 التأثير على مصادر المياه:}

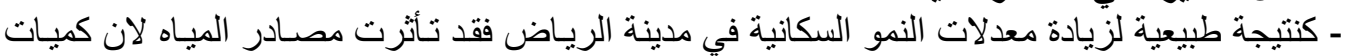

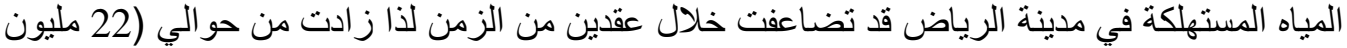

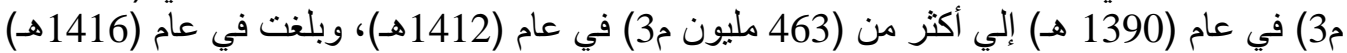

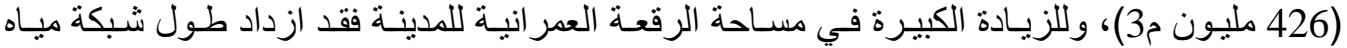

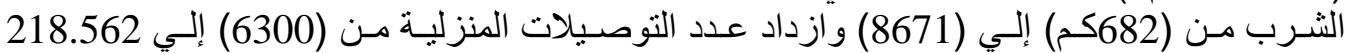

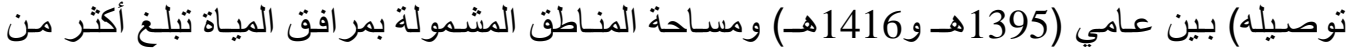

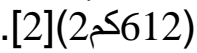

4-2-4 التأثير على الأودية:

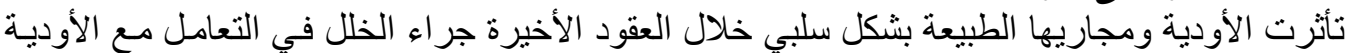

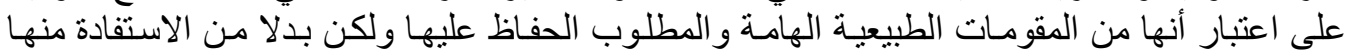

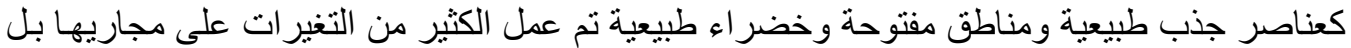

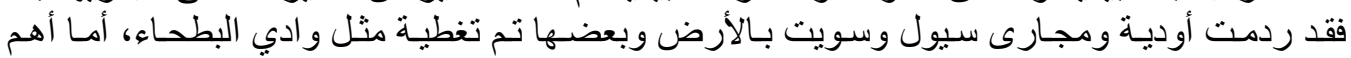

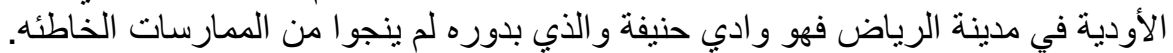

- في العقود الأخيرة انتشرت في وادي حنيفة العديد من الأنشطة الصناعبة خصوصا في مجال مواد الاد الئاد

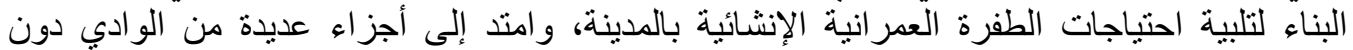

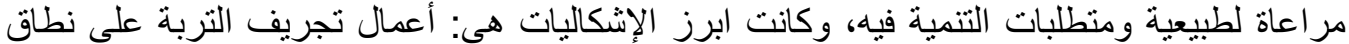

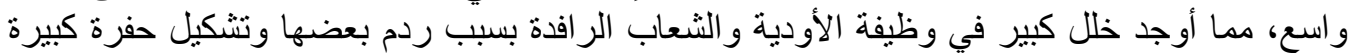

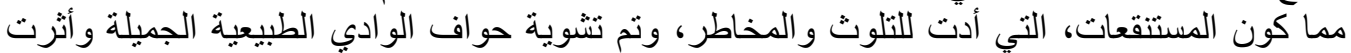

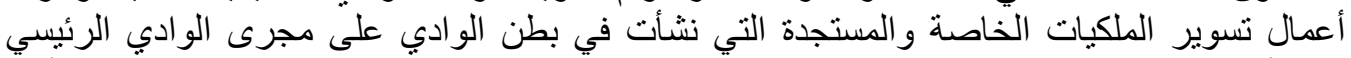

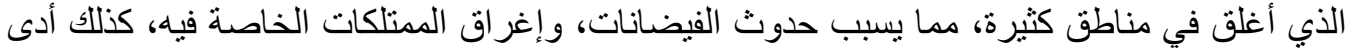

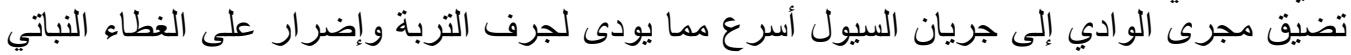
و الحياة الفطرية والتوازن الطبيعي [17].

\section{5-2-4 التأثير بزيادة التلوث من الصرف الصحي:}

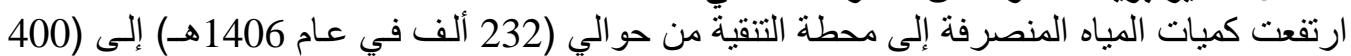

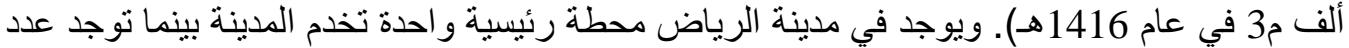

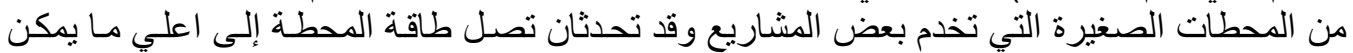

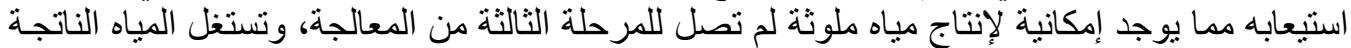

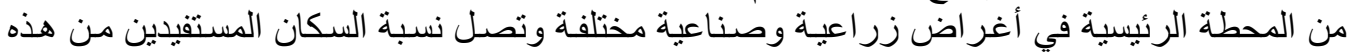

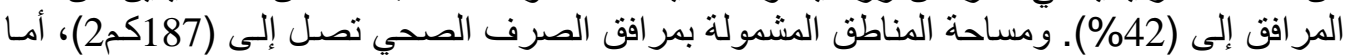

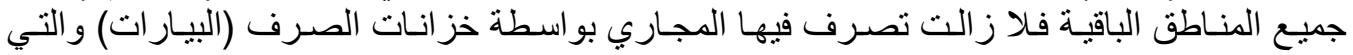
تتسبب بمشاكل صحية وتلوث للمياه السطحية و الجوفية. 


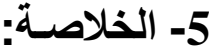

- خلصت هذه الدر اسة إلي وجود حاجة ملحة لمعالجة ظـاهرة النمو السكاني المتسـار ع لمدينـة الريـاض

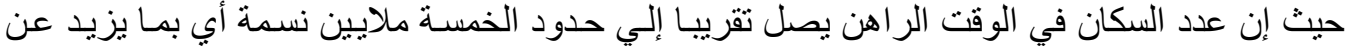

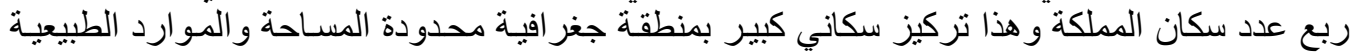

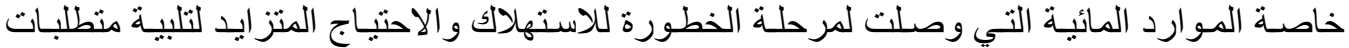

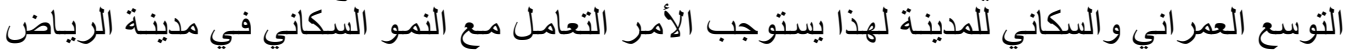
بنظرة شمولية و علي جميع المستويات الوطنية والإقليمية و المحلية و علي جميع القطاعات حتى لا لتفاقي

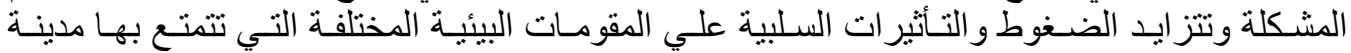

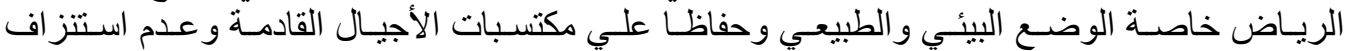
مواردهم البيئية.

- و العلاج يحتاج لوضع رؤية إستر اتيجية شاملة لجميع مناطق المملكة خاصة المناطق التي تصل منهـ التها

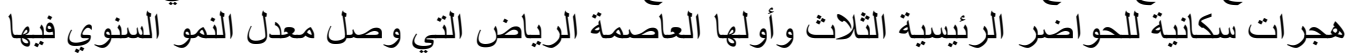

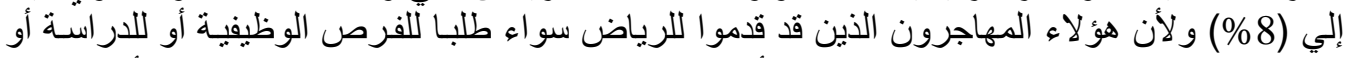

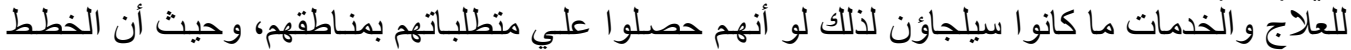

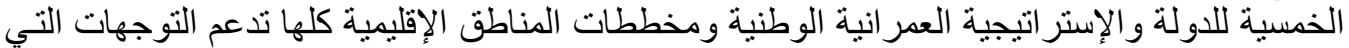

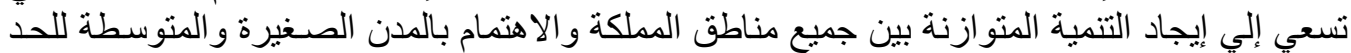

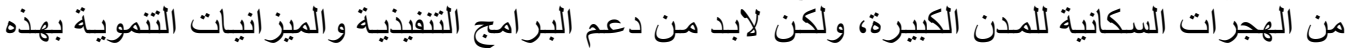

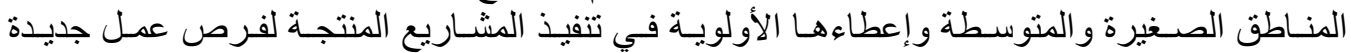

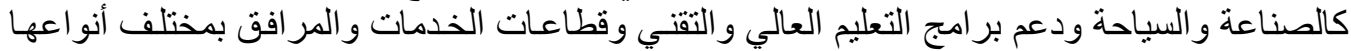

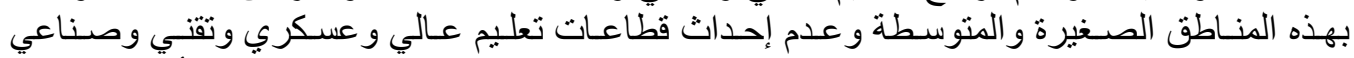

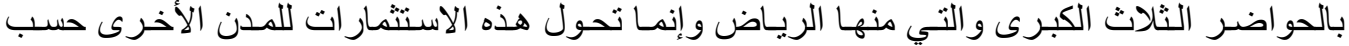
التوجهات الإستر اتيجية المتوازنة النيرة

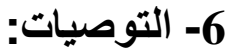

نتجت عن هذه الدر اسة بعض التوهئة التوصيات و هي كما يلي:

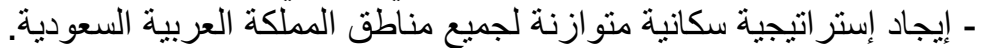

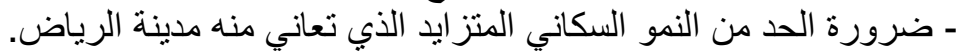

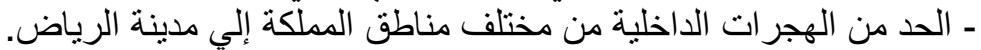

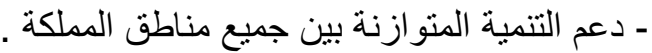

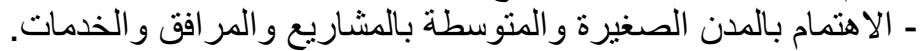

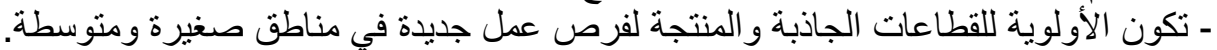

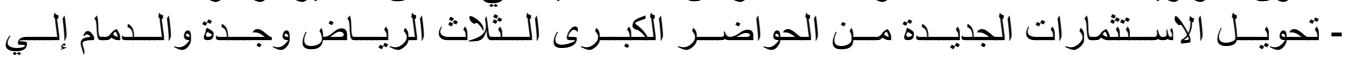

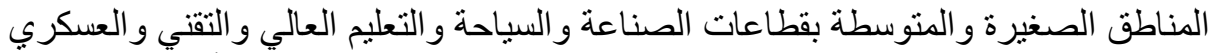

- وضع قيود وتعليمات و عقوبات صارمة للحفاظ علي المقومات البيئية و عدم الأضر ار بهار بها.

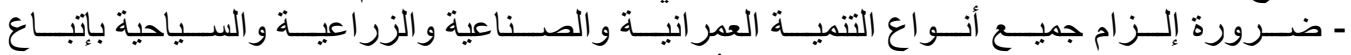

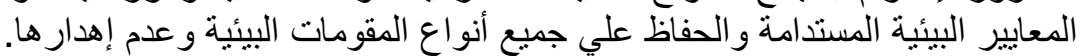

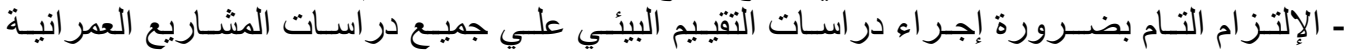

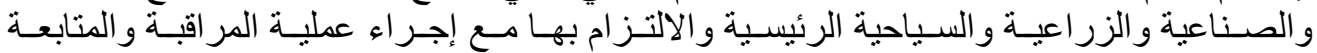

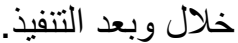

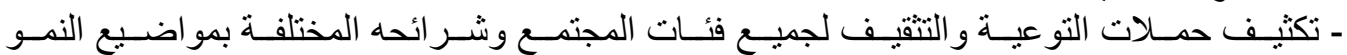

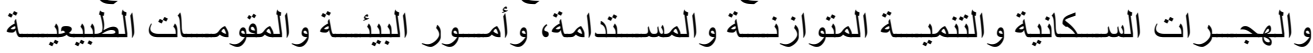


وضـرورة الحفـاظ عليهـا كتـروات نسـتفيد منهــا علـي قـدر الحاجـة بـدون أهـدار لحـق الأجيـال

تقرير الأوضـاع الر اهنـة وبدائل التنميـة، إستر اتيجية التنميـة العمر انيـة لمنطقة الريـاض، وزارة

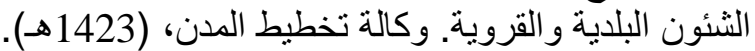

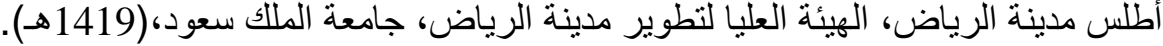

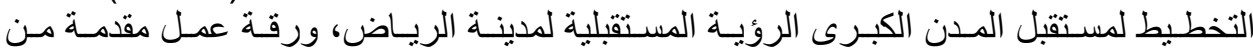

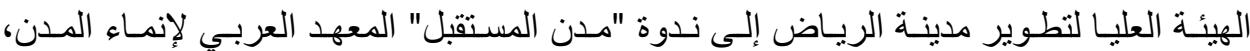

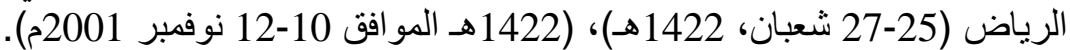

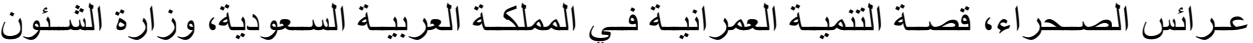
البلدية و القروية وكالة تخطيط المدن، المئ، (1419هـ).

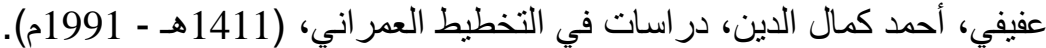

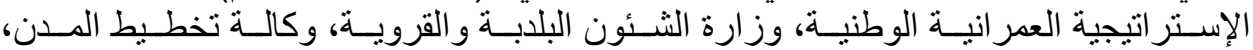

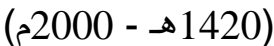

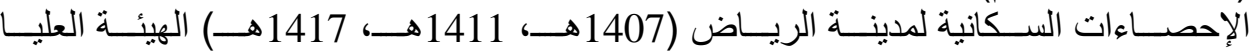

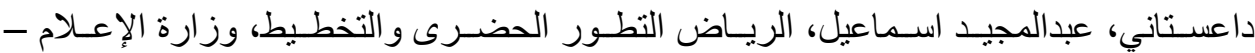

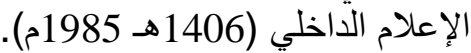

الهذلول، صـالح بـن على، المدينـة العربيـة الإسـلامية أثنر التشـريع في تكوين البيئة العمر انيـة

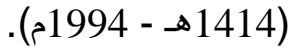

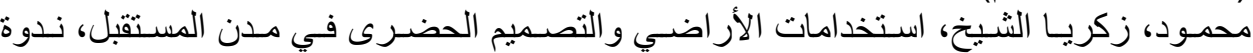

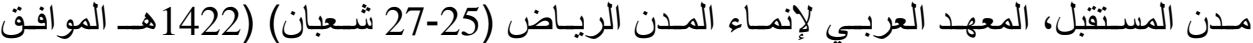

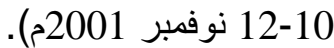

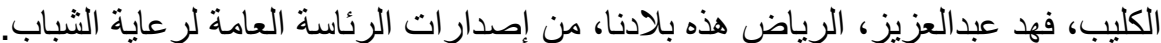

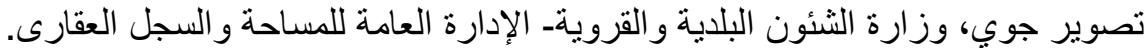

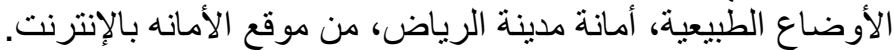

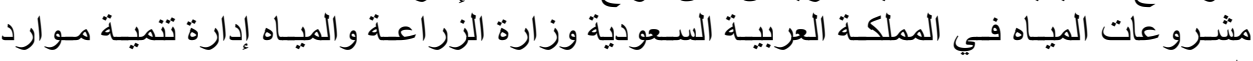

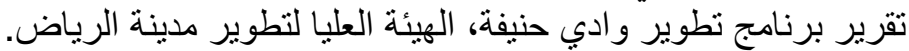

